NATIONAL LABORATORY

\title{
Shear Rolling of Magnesium Sheet for Automotive, Defense, and Energy Applications
}

\section{October 29, 2013}

\section{Prepared by}

G. Muralidharan, T. R. Muth, William H. Peter, T. R. Watkins, and Y. Wang Oak Ridge National Laboratory

Dave Randman, Bruce Davis, Marytn Alderman

Magnesium Elektron North America

Chris Romanoski

FATA Hunter

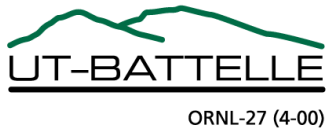




\title{
DOCUMENT AVAILABILITY
}

Reports produced after January 1, 1996, are generally available free via the U.S. Department of Energy (DOE) Information Bridge.

Web site http://www.osti.gov/bridge

Reports produced before January 1, 1996, may be purchased by members of the public from the following source.

\author{
National Technical Information Service \\ 5285 Port Royal Road \\ Springfield, VA 22161 \\ Telephone 703-605-6000 (1-800-553-6847) \\ TDD 703-487-4639 \\ Fax 703-605-6900 \\ E-mail info@ntis.gov \\ Web site http://www.ntis.gov/support/ordernowabout.htm
}

Reports are available to DOE employees, DOE contractors, Energy Technology Data Exchange (ETDE) representatives, and International Nuclear Information System (INIS) representatives from the following source.

Office of Scientific and Technical Information

P.O. Box 62

Oak Ridge, TN 37831

Telephone 865-576-8401

Fax 865-576-5728

E-mail reports@osti.gov

Web site http://www.osti.gov/contact.html

This report was prepared as an account of work sponsored by an agency of the United States Government. Neither the United States Government nor any agency thereof, nor any of their employees, makes any warranty, express or implied, or assumes any legal liability or responsibility for the accuracy, completeness, or usefulness of any information, apparatus, product, or process disclosed, or represents that its use would not infringe privately owned rights. Reference herein to any specific commercial product, process, or service by trade name, trademark, manufacturer, or otherwise, does not necessarily constitute or imply its endorsement, recommendation, or favoring by the United States Government or any agency thereof. The views and opinions of authors expressed herein do not necessarily state or reflect those of the United States Government or any agency thereof. 
Materials Science and Technology Division

\title{
SHEAR ROLLING OF MAGNESIUM SHEET FOR AUTOMOTIVE, DEFENSE, AND ENERGY APPLICATIONS
}

\author{
G. Muralidharan, T. R. Muth, William H. Peter, T. R. Watkins, E. Ohriner, and Y. Wang \\ Oak Ridge National Laboratory \\ Dave Randman, Bruce Davis, Marytn Alderman \\ Magnesium Elektron North America \\ Chris Romanoski \\ FATA Hunter
}

Date Published: October 29, 2013

\author{
Prepared by \\ OAK RIDGE NATIONAL LABORATORY \\ Oak Ridge, Tennessee 37831-6283 \\ managed by \\ UT-BATTELLE, LLC \\ for the \\ U.S. DEPARTMENT OF ENERGY \\ under contract DE-AC05-00OR22725
}




\section{CONTENTS}

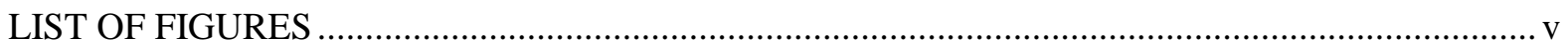

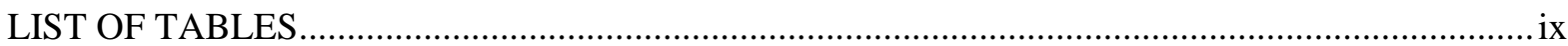

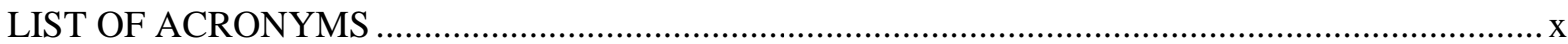

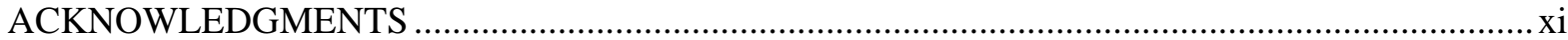

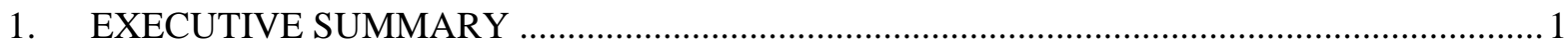

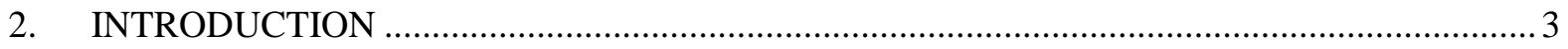

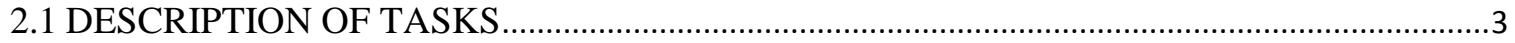

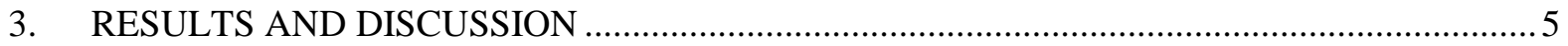

3.1 TASK 1: DESIGN, FABRICATE AND INSTALL SHEAR ROLLING MILL ..........................5

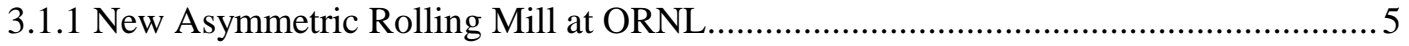

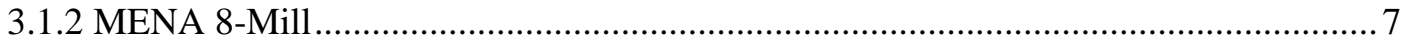

3.2 TASK 2: ALLOY SELECTION

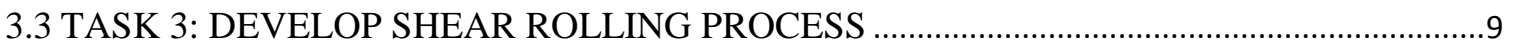

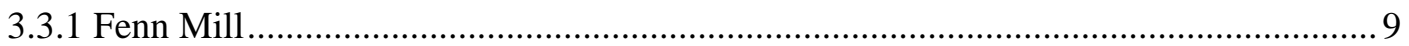

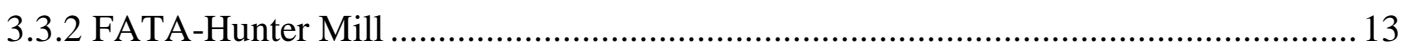

3.4 TASK 4: DEMONSTRATE SHEAR ROLLING IN AN INDUSTRIAL PROCESS

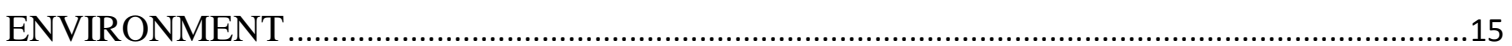

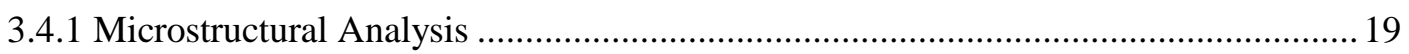

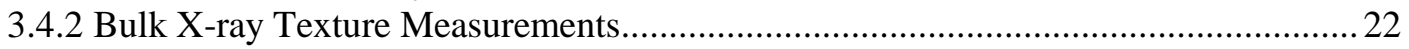

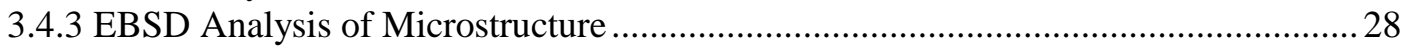

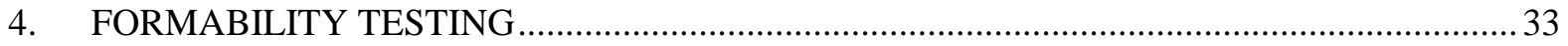

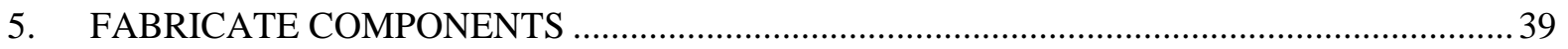

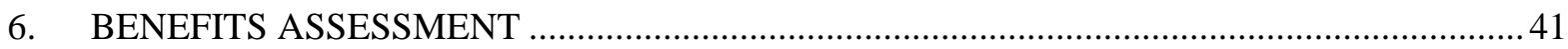

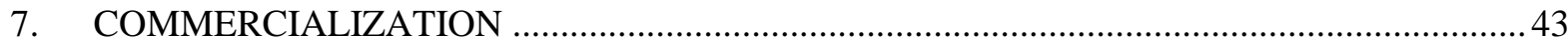

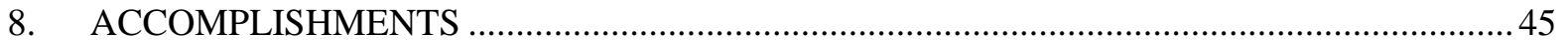

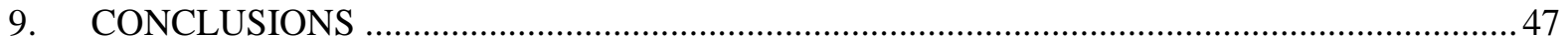

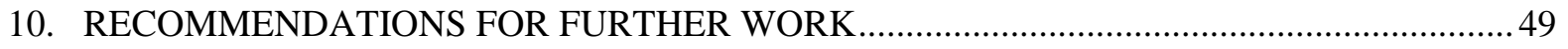

10.1 PHASE 2: DESIGN FOR COIL-TO-COIL OPERATION ……..................................................

10.2 ASYMMETRIC ROLLING PROCESS DEVELOPMENT AND EVALUATION ................49 


\section{LIST OF FIGURES}

FIG. 1. THE NEW ASYMMETRIC ROLLING MILL DESIGNED AND FABRICATED BY FATA HUNTER IN COLLABORATION WITH ORNL

FIG. 2. SCHEMATIC OF THE (A) SYMMETRIC ROLLING AND (B) ASYMMETRIC ROLLING

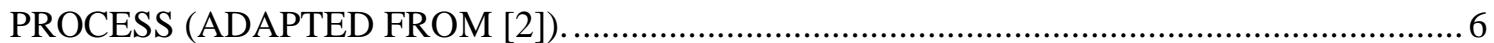

FIG. 3. 8-MILL AT MAGNESIUM ELEKTRON NORTH AMERICA'S FACILITY....................... 8

FIG. 4. INITIAL ROLLING TRIALS FOR (A) SYMMETRIC AND (B) ASYMMETRIC ROLLING SHOWED THAT AZ31B AND ZE10 (ZEK 100) SHOWED MINIMUM CRACKING AND GOOD SURFACE QUALITIES. ARROWS SHOWS SHEET WITH CRACKS AND THE RELATIVELY ROUGH (SERRATED) SURFACE. ........................................................... 8

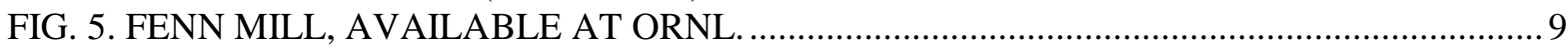

FIG. 6. A CRACK FORMED WITHIN A SHEAR BAND IN AZ31B ASYMMETRICALLY ROLLED WITH A SHEAR RATIO OF 3:1 ON THE FENN MILL AT $180^{\circ} \mathrm{C}$ WITH A TOTAL STRAIN OF $22 \%$.

FIG. 7. EFFECT OF TEMPERATURE AND DEFORMATION ON RECRYSTALLIZATION IN ASYMMETRICALLY ROLLED AZ31B (3:1) (A) $13 \%$ REDUCTION AT $135^{\circ} \mathrm{C}$, (B) $18 \%$ AT $180^{\circ} \mathrm{C}, \mathrm{AND}(\mathrm{C}) 38 \%$ AT $225^{\circ} \mathrm{C}$.

FIG. 8. TYPICAL $\{0002\}$ POLE FIGURE FROM AS-RECEIVED AZ31B. ROLLING DIRECTION IS VERTICAL (INTENSITY IN ARBITRARY UNITS) ...

FIG. 9. X-RAY TEXTURE MEASUREMENTS FROM A SPECIMEN ASYMMETRICALLY ROLLED TO A REDUCTION OF $38 \%$ AT $225^{\circ} \mathrm{C} .\{0002\}$ POLE FIGURES OBTAINED FROM (A) NEAR THE SURFACE IN CONTACT WITH THE FAST ROLL, (B) CENTERLINE, AND (C) NEAR THE SURFACE IN CONTACT WITH THE SLOW ROLL. ROLLING DIRECTION IS VERTICAL. INTENSITY IN ARBITRARY UNITS .

FIG. 10 MICROSTRUCTURE OF AZ31B SPECIMENS ROLLED AT $200^{\circ} \mathrm{C}$ (A) SYMMETRICALLY ROLLED AT 25\% REDUCTION (B) ASYMMETRICALLY ROLLED BY 25\% AT 1:1.35 SHEAR RATIO, AND (C) ASYMMETRICALLY ROLLED BY 40\% AT A RATIO OF 3:1

FIG. 11. X-RAY TEXTURE MEASUREMENTS FROM (A) A SPECIMEN PRIOR TO ASYMMETRIC ROLLING, (B) SYMMETRICALLY ROLLED AT $200^{\circ} \mathrm{C}, 25 \%$ REDUCTION, AND (C) ASYMMETRICALLY ROLLED BY 25\% AT 1:1.35 SHEAR RATIO AT A TEMPERATURE OF $200^{\circ} \mathrm{C}$. ROLLING DIRECTION IS VERTICAL. INTENSITY SHOWN IS NORMALIZED TO INTENSITY FROM A RANDOMLY ORIENTED SPECIMEN..

FIG. 12. EFFECT OF PROCESSING CONDITION ON QUALITY OF SHEET PRODUCED USING THE 8-MILL. THE PHOTOGRAPH ON THE LEFT SHOWS ZEK100 ROLLED AT $425^{\circ} \mathrm{C}$ WITH $10 \%$ REDUCTION. THE PHOTOGRAPH ON THE RIGHT SHOWS AZ31B ROLLED AT $200^{\circ} \mathrm{C}$ WITH $50 \%$ REDUCTION.

FIG. 13. PHOTOGRAPH OF ROLLED SHEETS SHOWING THE DIFFERENCE IN SHAPE CONTROL ALONG THE LENGTH.

FIG. 14. SECTION THROUGH A DRILLED HOLE IN A SAMPLE DEFORMED ASYMMETRICALLY AT $370^{\circ} \mathrm{C}$ WITH $10 \%$ REDUCTION. THE TOP SURFACE WAS IN CONTACT WITH THE FAST ROLL AND THE BOTTOM SURFACE WITH THE SLOW ROLL. THE ROLLING DIRECTION WAS LEFT TO RIGHT.

FIG. 15. SECTION THROUGH A DRILLED HOLE IN A SAMPLE DEFORMED ASYMMETRICALLY AT $370^{\circ} \mathrm{C}$ WITH 50\% REDUCTION. THE TOP SURFACE WAS IN CONTACT WITH THE FAST ROLL AND THE BOTTOM SURFACE WITH THE SLOW ROLL. THE ROLLING DIRECTION WAS LEFT TO RIGHT. 
FIG. 16. OPTICAL MICROGRAPHS OF AZ31B (LEFT) AND ZEK100 (RIGHT) FEED STOCK MATERIALS.

FIG. 17. AZ31B ROLLED AT $250^{\circ} \mathrm{C}$ WITH $10 \%$ REDUCTION ON 8-MILL IN (A) SYMMETRIC

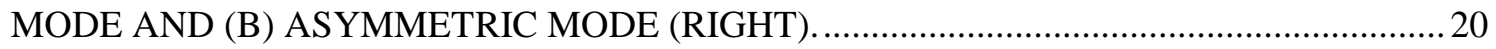

FIG. 18. AZ31B ROLLED AT $250^{\circ} \mathrm{C}$ WITH 50\% REDUCTION ON 8-MILL IN (A) SYMMETRIC

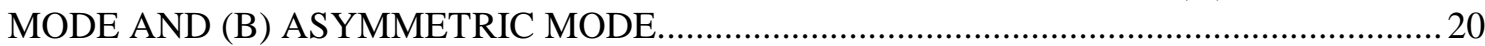

FIG. 19. ZEK100 ROLLED AT $250^{\circ} \mathrm{C}$ WITH $10 \%$ REDUCTION ON 8 MILL IN SYMMETRIC

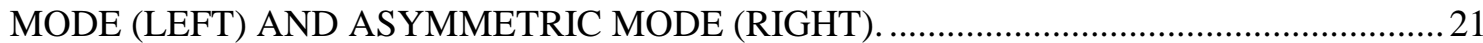

FIG. 20. ZEK100 ROLLED AT $250^{\circ} \mathrm{C}$ WITH 50\% REDUCTION ON 8 MILL IN SYMMETRIC

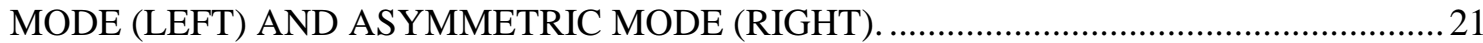

FIG. 21. AZ31B (LEFT) AND ZEK100 (RIGHT) SHEAR ROLLED IN A MULTIPASS SCHEDULE AT $225^{\circ} \mathrm{C}$ TO A TOTAL STRAIN OF APPROXIMATELY 50\% ON THE FENN MILL SHOWING THE MICROSTRUCTURAL VARIATION CLOSE TO THE SLOW ROLL (TOP) AND FAST ROLL (BOTTOM) SURFACE.

FIG. 22. XRD 0002 POLE FIGURE FOR AZ31B FEEDSTOCK (ROLLING DIRECTION IS HORIZONTAL). INTENSITY SHOWN IN ARBITRARY UNITS........................................2 23

FIG. 23. XRD 0002 POLE FIGURES FOR AZ31B ROLLED AT $250^{\circ} \mathrm{C}$ WITH $10 \%$ REDUCTION IN (A) SYMMETRIC MODE AND (B) ASYMMETRIC MODE. INTENSITY SHOWN IN ARBITRARY UNITS

FIG. 24. XRD 0002 POLE FIGURES FOR AZ31B ROLLED AT $250^{\circ} \mathrm{C}$ WITH $50 \%$ REDUCTION IN (A) SYMMETRIC MODE AND (B) ASYMMETRIC MODE (RIGHT). INTENSITY SHOWN IN ARBITRARY UNITS.

FIG. 25. XRD 0002 POLE FIGURES FOR AZ31B ROLLED AT $425^{\circ} \mathrm{C}$ WITH $10 \%$ REDUCTION IN (A) SYMMETRIC MODE AND (B) ASYMMETRIC MODE (RIGHT). INTENSITY SHOWN IN ARBITRARY UNITS.

FIG. 26. XRD 0002 POLE FIGURES FOR AZ31B ROLLED AT $425^{\circ} \mathrm{C}$ WITH $50 \%$ REDUCTION IN (A) SYMMETRIC MODE AND (B) ASYMMETRIC MODE (RIGHT). INTENSITY SHOWN IN ARBITRARY UNITS.

FIG. 27. XRD 0002 POLE FIGURE FOR ZEK100 FEEDSTOCK. INTENSITY SHOWN IN ARBITRARY UNITS

FIG. 28. XRD 0002 POLE FIGURES FOR ZEK100 ROLLED AT $250^{\circ} \mathrm{C}$ WITH $10 \%$ REDUCTION IN (A) SYMMETRIC MODE AND (B) ASYMMETRIC MODE. INTENSITY SHOWN IN ARBITRARY UNITS

FIG. 29. XRD 0002 POLE FIGURES FOR ZEK100 ROLLED AT $250^{\circ} \mathrm{C}$ WITH $50 \%$ REDUCTION IN (A) ASYMMETRIC MODE AND (B) ASYMMETRIC MODE. INTENSITY SHOWN IN ARBITRARY UNITS

FIG. 30. XRD 0002 POLE FIGURES FOR ZEK100 ROLLED AT $425^{\circ} \mathrm{C}$ WITH $10 \%$ REDUCTION IN (A) SYMMETRIC MODE AND (B) ASYMMETRIC MODE. INTENSITY SHOWN IN ARBITRARY UNITS

FIG. 31. XRD 0002 POLE FIGURES FOR ZEK100 ROLLED AT $425^{\circ} \mathrm{C}$ WITH $50 \%$ REDUCTION IN SYMMETRIC MODE (LEFT) AND ASYMMETRIC MODE (RIGHT). INTENSITY SHOWN IN ARBITRARY UNITS.

FIG. 32. EBSD MAP (IPF COLORING) OF AN AZ31B SHEET ROLLED SYMMETRICALLY AT $250^{\circ} \mathrm{C}$ WITH $10 \%$ REDUCTION (MAP TAKEN AT THE SHEET CENTERLINE.) ..............28

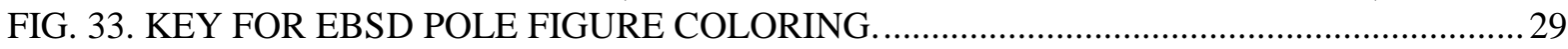

FIG. 34. EBSD MAPS (IPF COLORING) OF ZEK100 SHEET ROLLED (A) SYMMETRICALLY AND (B) ASYMMETRICALLY AT $250^{\circ} \mathrm{C}$ WITH $10 \%$ REDUCTION. MAPS TAKEN AT THE CENTERLINE OF THE SHEET.

FIG. 35. EBSD MAPS (IPF COLORING) OF ZEK100 SHEET ROLLED SYMMETRICALLY (LEFT) AND ASYMMETRICALLY (RIGHT) AT $425^{\circ} \mathrm{C}$ WITH $10 \%$ REDUCTION. MAPS 
TAKEN AT THE CENTERLINE OF THE SHEET.

FIG. 36. EBSD MAP (IPF COLORING) OF A ZEK100 SHEET ROLLED ASYMMETRICALLY AT $250^{\circ} \mathrm{C}$ WITH $50 \%$ REDUCTION (MAP TAKEN AT THE SHEET CENTERLINE.).........31

FIG. 37. FIXTURE USED FOR TESTING THE FORMABILITY OF MAGNESIUM SHEET........ 33

FIG. 38. TYPICAL FORMED SHEETS OBTAINED FROM DOME TESTS ON AZ31B AND ZEK 100 SHEETS ROLLED AT $425^{\circ} \mathrm{C}$ TO A 50\% REDUCTION IN THICKNESS

FIG. 39. ANNEALING OF AZ31B RESULTS IN DECREASED FORMABILITY (ANNEALED SPECIMEN ON THE RIGHT)

FIG. 40. RESULTS FROM DOME TESTS ON AZ31-B IN THE ANNEALED CONDITION AND IN AS-ROLLED CONDITION (ASYMMETRICALLY ROLLED). ASYMMETRIC ROLLING CAN EITHER IMPROVE FORMABILITY (BLUE LINE) OR DECREASE FORMABILITY (RED LINE) DEPENDING ON THE PROCESSING CONDITIONS. .

FIG. 41. PHOTOGRAPH SHOWING PARTS FORMED AT SUPERFORM..................................39

FIG. 42. PHOTOGRAPH SHOWING A PART FORMED AT SUPERFORM FOR GM FROM SHEAR ROLLED ZEK100. 


\section{LIST OF TABLES}

TABLE 1. INITIAL PARAMETERS EMPLOYED ON THE FENN MILL AT ORNL WITH 3:1

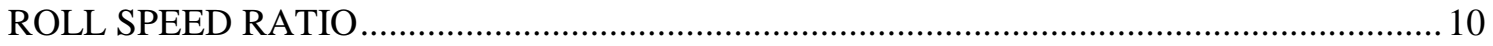

TABLE 2. ROLLING CONDITIONS FOR MAGNESIUM ALLOY STRIPS ROLLED ON THE

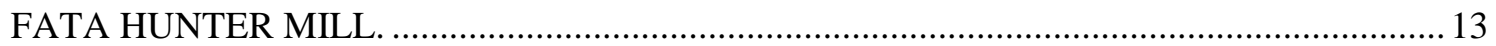

TABLE 3. MATRIX OF PARAMETERS USED FOR ROLLING SHEET USING THE 8-MILL AT

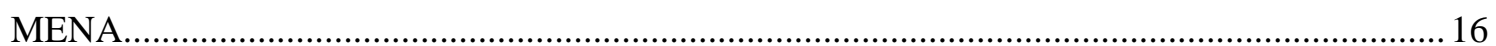

TABLE 4. EFFECT OF PROCESSING CONDITIONS ON LIMITING DOME HEIGHTS AT $175^{\circ} \mathrm{C}$

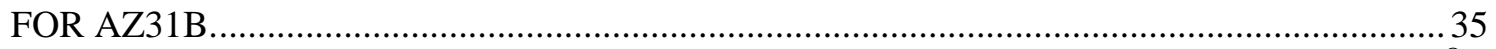

TABLE 5. EFFECT OF PROCESSING CONDITIONS ON LIMITING DOME HEIGHTS AT $175^{\circ} \mathrm{C}$

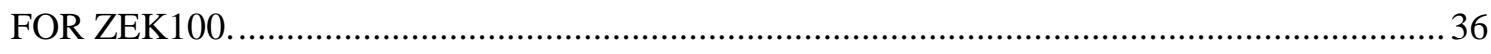




\section{LIST OF ACRONYMS}

$\begin{array}{ll}\text { ARRA } & \text { American Recovery and Reinvestment Act } \\ \text { DSR } & \text { Differential Speed Rolling } \\ \text { EBSD } & \text { Electron Back Scatter Diffraction } \\ \text { EDXA } & \text { Energy Dispersive X-ray Analysis } \\ \text { fpm } & \text { feet per minute } \\ \text { HCP } & \text { Hexagonal Close Packed } \\ \text { IPF } & \text { Inverse Pole Figure } \\ \text { MENA } & \text { Magnesium Elektron North America } \\ \text { OEM } & \text { Original Equipment Manufacturer } \\ \text { ORNL } & \text { Oak Ridge National Laboratory } \\ \text { PID } & \text { Proportional Integral Derivative } \\ \text { SEM } & \text { Scanning Electron Microscope } \\ \text { XRD } & \text { X-ray Diffraction }\end{array}$




\section{ACKNOWLEDGMENTS}

This work was funded under the American Recovery and Reinvestment Act (ARRA) by the U.S. Department of Energy, Office of Energy Efficiency and Renewable Energy, Advanced Manufacturing Office, under contract DE-AC05-00OR22725 with UT-Battelle, LLC and managed as CPS Agreement Number 20913. Funding for X-ray texture and Electron Back Scatter Diffraction (EBSD)

measurements was provided by the High Temperature Materials User Program of Oak Ridge National Laboratory, which is sponsored by the U.S. Department of Energy, Office of Energy Efficiency and Renewable Energy, Vehicle Technologies Program.

The authors would like to thank Dr. Eliot Specht for texture measurements, Alina Lowden for formability testing, Jackie Mayotte for metallography and Dave Harper, Greg Cox, Kevin Harper, and Larry Lowe for their technical support. Also, we would like to thank Rita Ayers for her administrative assistance with the report. 



\section{EXECUTIVE SUMMARY}

Magnesium is the lightest structural metal known: at approximately $1 / 5$ the density of steel, $1 / 2$ the density of titanium and $2 / 3$ the density of aluminum. Hence magnesium alloys represent potential weight savings across the entire transportation industry. The major hurdle to the deployment of magnesium products by the transportation industry is the price barrier that exists due to the current high cost of producing magnesium alloy sheet on a volume basis. Proven technology (e.g., twin roll sheet casting and hot reversing coil mill technology) exists which could lower the cost of magnesium alloy sheet by as much as 50\%, but needs to be demonstrated and implemented in high volume production to achieve benefits. In addition, the predominant basal texture (alignment of basal planes parallel to the sheet surface) that exists in magnesium alloy sheet results in poor low temperature formability resulting in added fabrication costs. Cost reduction achieved through energy efficiency, coupled with even greater energy savings by deployment of this "lightest of metals", will help the United States achieve its goal to eliminate dependence on foreign fossil fuel. Oak Ridge National Laboratory (ORNL), Magnesium Elektron North America (MENA), and FATA Hunter collaborated on this project to develop shear rolling technology of magnesium sheet to enable improvement of the formability of magnesium sheet while addressing cost and lower energy consumption.

The key to improving the formability of magnesium sheet is to modify the predominantly basal texture that develops in magnesium alloy sheets due to traditional casting and rolling techniques. As part of this project, a new laboratory scale asymmetric rolling mill with unique capabilities was designed and fabricated to enable asymmetric rolling of magnesium alloy sheets. This mill won an R \& D 100 award in 2012. Samples of magnesium alloys AZ31B and ZEK100 were asymmetrically rolled on three different mills to understand the effects of asymmetric rolling conditions on texture, microstructure, and formability. Microstructural studies showed that the grain structure, including the extent of recrystallization was affected by shear deformation, \% reduction, and temperature. In addition, a distinctly different grain structure was observed close to the surfaces with the material adjoining the slower roll surface showing the presence of finer grains. Texture was significantly affected by asymmetric rolling, resulting in tilting of the basal poles towards the rolling direction. AZ31B showed a standard basal texture but ZEK100 developed a 'rare earth texture' after recrystallization, which would be expected to lead to better formability. Formability tests (dome tests) were performed on sheets to understand the effect of the shear rolling process conditions on the limiting dome height achieved at a temperature of approximately $175^{\circ} \mathrm{C}$. Dome testing showed that formability measured by the limiting dome height is extremely sensitive to the asymmetric rolling path and formability testing procedures. Results showed that certain shear rolling paths resulted in improved formability of AZ31B sheet.

Wide sheets (36"x72") were rolled at MENA to investigate any issues arising from larger scale shear rolling. The wide sheet obtained from rolling at MENA was also successfully used to demonstrate the forming of two different demonstration automotive parts. Results from this project have thus clearly demonstrated that texture modification can be achieved through shear rolling and this process is amenable to high throughput industrial processing. 


\section{INTRODUCTION}

Higher cost of sheet production and the lower formability relative to steel and aluminum are two major factors inhibiting the widespread use of magnesium alloys in automotive applications. Magnesium's lower formability is associated with its hexagonal closest packed (HCP) crystal structure, which has a relatively lower number of slip systems that are active to accommodate deformation when compared to aluminum and steel. Furthermore, conventionally rolled magnesium sheet has a strong basal texture component that results in anisotropy of its tensile properties. The conventional symmetric rolling process aligns the basal planes parallel to the rolling plane, with a 5-10 degree tilt forward and aft of the rolling direction ${ }^{1}$. It is this tilt that produces the anisotropy. Weakening or randomization of the basal texture in magnesium sheet will reduce this effect and improve formability. Asymmetric (also referred to as Differential Speed Rolling (DSR) or shear rolling) has been shown to tilt this basal texture away from the sheet normal along the rolling direction, resulting in improved formability ${ }^{2}$. Shear rolling uses two work rolls travelling at different speeds to impart a shear component to the stresses and strains experienced by the material. The purpose of this project was to demonstrate the feasibility of shear or asymmetric rolling of magnesium alloy sheets on the laboratory and industrial scale, evaluate the formability of such processed sheet and demonstration fabrication of trial industrial components.

\subsection{DESCRIPTION OF TASKS}

This project was initiated by Oak Ridge National Laboratory (ORNL) in collaboration with Magnesium Elektron North America (MENA), and was structured into five tasks:

Task 1: Design, fabricate, and install "Shear" roll mill: The primary focus of this task was to design and install a new "laboratory scale" shear rolling mill at ORNL. To enable industrial scale production and for effective transfer of technology, another focus of this task was to design and install a "shear" rolling capability on the factory floor in MENA.

Task 2: Alloy selection for improved formability: While preliminary experiments in the literature show that shear rolling can improve formability in some commercial magnesium alloys, there was a need to explore materials that would tend to benefit the most from this technology. The purpose of this task was to down-select the most appropriate alloys for further process development based upon the data available and existing industrial needs.

Task 3: Develop manufacturing shear rolling process technology for alloys: The primary goal of this task was to develop the parameters for processing of sheets of the alloys identified in Task 2 . The focus of the processing was to achieve appropriate thicknesses, and to develop textures that would have the potential to improve formability of the sheets.

Task 4: Demonstrate shear roll process technology in an industrial process environment: Based upon the processing trials performed at ORNL, it was proposed that industrial-scale shear rolling would be performed at MENA to enable completion of Task 5.

1 Agnew S.R. and Duygulu O. (2005) Plastic anisotropy and the role of non-basal slip in magnesium alloy AZ31B, Int. J. of Plasticity, 21, pp1161-1193

2 Xinsheng Huang*, Kazutaka Suzuki, Akira Watazu, Ichinori Shigematsu, Naobumi Saito, Microstructure and texture of Mg-Al-Zn alloy processed by differential speed rolling, Journal of alloys and compounds, 457(2008), 408-412. 
Task 5: Fabricate at least two components using materials processed with the newly developed manufacturing processing technology: It was proposed that two components would be fabricated with the magnesium alloys sheet materials manufactured using the newly developed shear roll processing technology outlined in Task 4. 


\section{RESULTS AND DISCUSSION}

\subsection{TASK 1: DESIGN, FABRICATE AND INSTALL SHEAR ROLLING MILL}

\subsubsection{New Asymmetric Rolling Mill at ORNL}

To reduce the conversion cost and make magnesium sheet truly competitive for automotive applications, the inefficiencies and high costs associated with the conventional warm rolling process and the resultant poor formability needed to be addressed. The asymmetric rolling mill was specifically designed to address both these needs. In 2010 FATA Hunter cooperated with Oak Ridge National Laboratory and Magnesium Elektron North America to develop a pilot rolling mill for magnesium sheet, see Figure 1. The purpose of this mill was to test a series of design concepts. These concepts were critical to the development of a commercial rolling mill that could cost-effectively process high quality magnesium sheet for the consumer market. These two major concepts were:

1. Rolling sheet between rolls that are rotating at different velocities-"Asymmetric Rolling" and 2. Roll heating to accomplish rolling using warm rolls - up to a temperature of $300^{\circ} \mathrm{C}$.

Rolling is a process where the thickness of sheet or plate is reduced sequentially to a desirable thickness by inserting it between two rotating rolls that are separated by a "roll gap" that is smaller than the thickness of the incoming sheet. Symmetric rolling (or normal rolling) is accomplished when the two rolls are operated at equal velocities and the sheet or plate undergoes plane strain compression; see Figure 2 (a). Asymmetric rolling (or shear rolling) is accomplished when the two rolls are rotating at different velocities thus imparting shear component to the sheet or plate deformation in addition to the plane strain compression. Prior research has demonstrated that asymmetric rolling allows rotation of the basal planes away from the rolling plane, thus reducing the basal texture and improving formability. In particular, the improvement in formability implies that forming can be accomplished at lower temperatures than is currently feasible with a corresponding decrease in the cost of formed components.

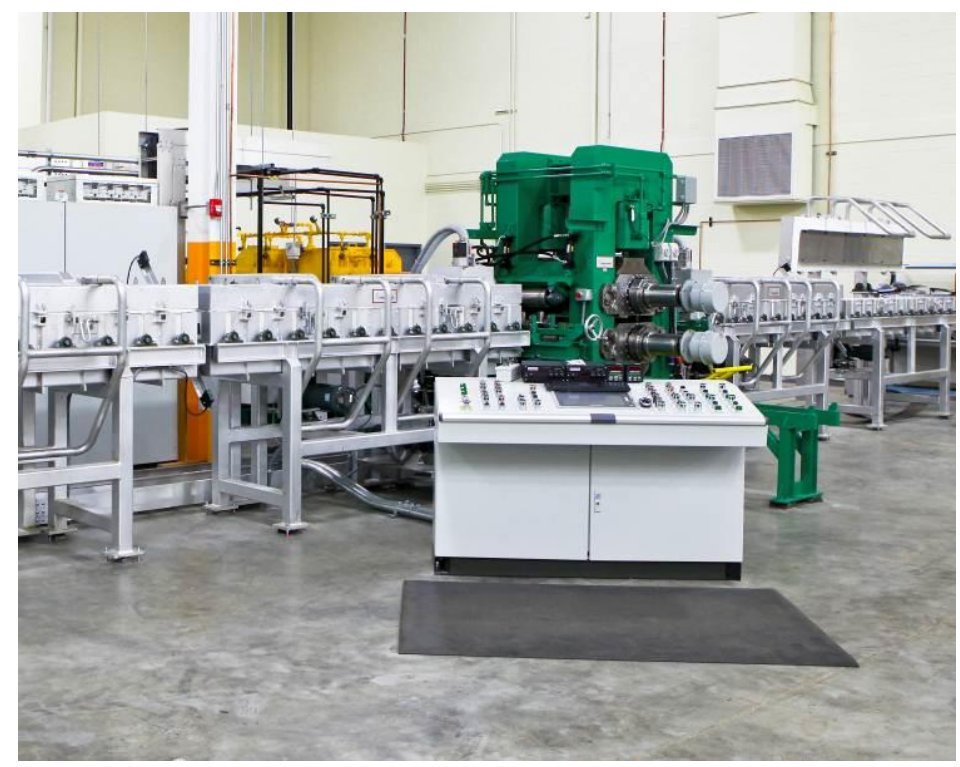

Fig. 1. The new asymmetric rolling mill designed and fabricated by FATA Hunter in collaboration with ORNL. 
Preliminary work on a laboratory scale mill equipped with unequal sized rolls showed that such shear deformation placed significantly higher demands on the torque requirements of the drivetrain and the ability of the rolls to accommodate such large torques. The new asymmetric mill was specifically designed with a large torque capability to accommodate a wide range of differential velocities and shear ratios. In addition, active dynamic braking was used to maintain the large difference in roll linear velocities. It should be noted that the mill is designed to accommodate up to a 5:1 velocity ratio with potentially higher values achievable with smaller reductions.

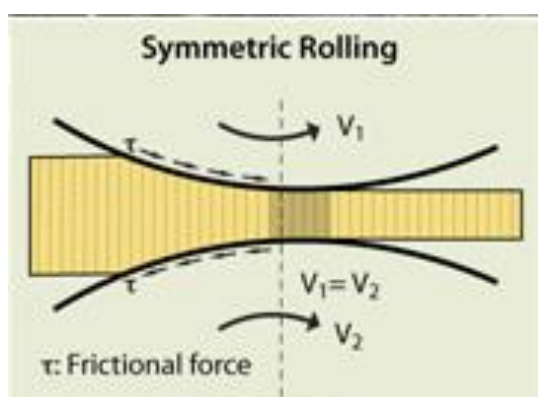

(a)

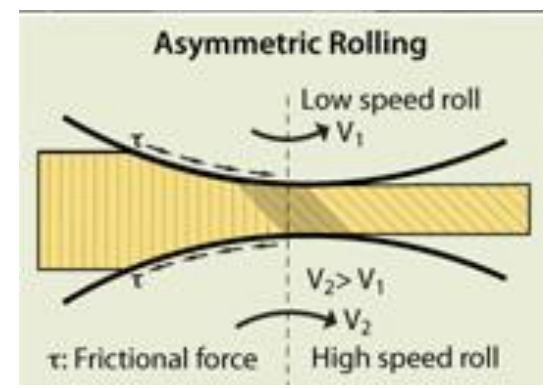

(b)

Fig. 2. Schematic of the (a) symmetric rolling and (b) asymmetric rolling process (adapted from [2]).

Roll heating is another key component of the newly designed mill with the potential to achieve the desired texture and properties of the processed sheet. The deformation mode of magnesium alloys is very strongly dependent on temperature. While the magnesium sheet can be heated to desired operating temperatures and rolled using cold rolls, the contact of the warm sheet with the cold rolls results in roll chilling of the sheet, resulting in unpredictable consequences for the deformation behavior of the sheet produced using this process. While external roll heating can be accomplished, such heating cannot be controlled easily to maintain isothermal roll temperatures. Thus this mill was designed with internal roll heating that can be used to maintain the rolls at a desired temperature using Proportional Integral Derivative (PID) control, thus defining the process conditions precisely. This ability greatly enhanced the reproducibility of the process conditions, while allowing the widest achievable process window for development.

The basic configuration of the laboratory scale mill consisted of a 2-Hi mill stand complete with hydraulic gap control, exhaust hood, side guides and pinch rolls mounted on a sub-base. The roll changer rails were mounted on a separate assembly that attached to the main sub-base. The mill incorporated asymmetric drives that were mounted on a separate base and connected to the mill via spindle couplings. The drives featured two-speed gearboxes for quick changes between the 50 and 500 feet per minute (fpm) speed range. Material handling was by means of two powered roller tables on each side of the mill. Each roller table can be controlled individually and the drives are interlocked and synchronized with the speed and direction of the mill. Each roller table was provided with a hinged cover that contained a thermostatically controlled electric heater and blower motor to minimize heat losses from the rolled strip. The main design features of the mill are summarized as follows:

- The mill has H13 tool steel work rolls that were sized for the optimum combination of

- Roll neck size (for bearing capacity and roll neck shear/torsional stress),

○ Roll body size (for roll rigidity and sufficient bite angle to take the required rolling reductions),

○ Contact length (to control heat transfer between the strip and the roll). 
- The rolls incorporate high energy density internal electric roll heaters that were specially developed for this application. The heaters incorporate a unique sheath that makes intimate thermal contact with the roll. Implementing and proving this design feature was a critical step in advancing this technology to the industrial scale. Temperatures of up to $300^{\circ} \mathrm{C}$ can be achieved with the use of these internal heaters.

- The mill had 245 tons of roll separating force to roll the hard magnesium alloys and to make the large reductions needed to ensure a fine recrystallized grain size.

- Each mill drive has 545,000 in.-lb of torque to not only accommodate the high reduction capability of the mill, but also provide the capacity for high asymmetric rolling ratios. In principle, the differential speeds between the two rolls can be very large, essentially limited only by this torque capacity. This was the first time that such a high ratio asymmetric drive had been used beyond laboratory table-top testing. This asymmetry increases both the internal shear stress and internal heat for any reduction, thus reducing the basal texture of the Hexagonal Close Packed (HCP) metal and stimulating grain refinement. This capability is critical in improving the formability of the magnesium alloy sheet produced on the mill and is an important factor in commercializing the technology.

- The mill has a quick gear change feature that allows the mill to be used for investigating the effect of higher rolling speeds on the microstructure of the magnesium sheet.

- The mill roll force cylinders are equipped with very accurate position transducers to enable the mill to operate in either gap mode or pressure mode with bumpless transfer between modes. The control system utilized for this mill is a simplified version of the controls found on FATA Hunter's full-size industrial aluminum mills.

- The mill incorporated a sub-base that not only allows for the mill to be pre-assembled, tested, and shipped as a unit, but it also greatly simplified the on-site installation at ORNL. The subbase also acted as the mounting base to facilitate a future upgrade to coil-to-coil operation and as a drain pan for roll lubricant.

- The heated roller tables have a modular design to allow for easy transportation and installation.

- The roller table heaters use hot air to eliminate the inherent dangers associated with radiant heating of magnesium. The heaters assist in maintaining the temperature required to roll the magnesium alloys in an isothermal condition.

- The mill incorporates a roll-out type roll changer for easy access to the work rolls.

\subsubsection{MENA 8-Mill}

As part of the technology transfer process, 8-Mill at Magnesium Elektron North America was selected as the mill that would be modified to demonstrate industrial scale practice of asymmetric or shear rolling. 8-Mill was an industrial mill with 48-inch wide rolls, (Figure 3). It has a single drive motor and thus the conversion to shear rolling required different diameter rolls. The maximum shear ratio that could be carried out on 8-Mill was limited by the design of the mill; the small roll could be no smaller than the chocks in which it sits and the top backup roll could be raised no higher than the top of the screw, limiting the size of the large upper roll. This meant that the maximum shear ratio possible was 1:1.35 with rolls of 14.457" and 19.500". To achieve this position of the upper roll, a new spindle was required as the old wobbler joint could not work at this angle. Therefore, a new spindle using universal couplings was acquired and the modifications were completed. 


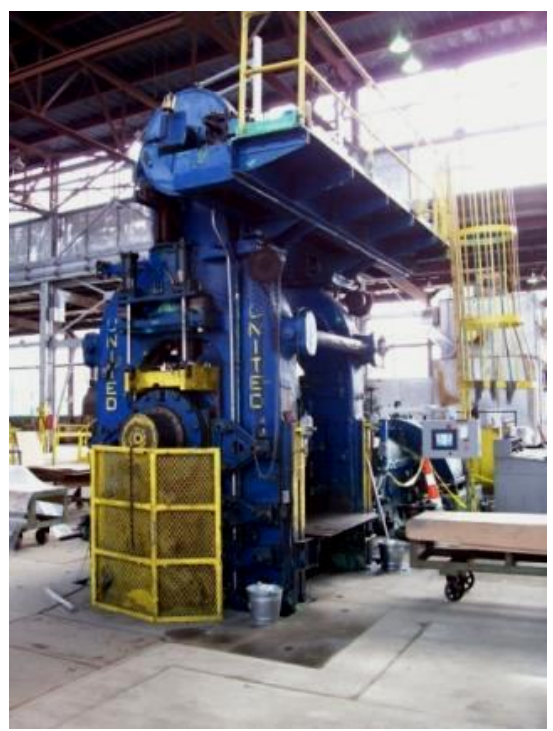

Fig. 3. 8-Mill at Magnesium Elektron North America's facility.

\subsection{TASK 2: ALLOY SELECTION}

Four different magnesium alloys in the form of sheet were initially studied to develop an understanding of differences in behavior under shear rolling conditions. These alloys include AZ31B (Mg-3wt\%Al-1wt\%Zn-0.3wt\%Mn), K1A (Mg-<1wt\%Zr), ZK10 (Mg-1wt\%Zn-<1wt\%Zr) and ZEK100 (Mg-1wt\%Zn- $<1 \mathrm{wt} \%$ Rare Earths- $<1 \mathrm{wt} \% \mathrm{Zr}$ ). The alloy sheets were supplied by MENA and are commercially available in bulk quantities. Preliminary trials on asymmetric rolling were conducted using the 3:1 sized rolls in the ORNL Fenn Mill. In these preliminary trials, it was found that when processed using a fixed set of parameters, AZ31B and ZEK100 performed the best amongst the four alloys as shown in Figure 4. It should be noted that ZK10 particularly showed significant cracking as shown in the figure. Thus, AZ31B and ZEK100 were down selected for further study in this project based upon the good surface quality and minimum cracking observed in the preliminary trials.

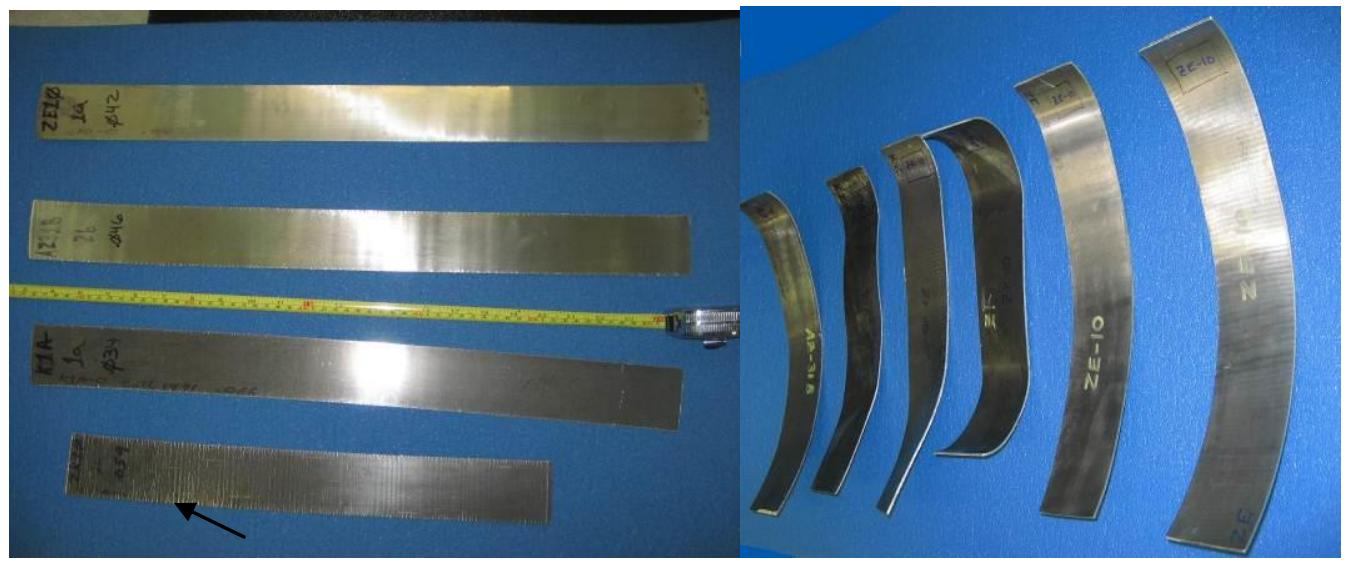

(a)

(b)

Fig. 4. Initial rolling trials for (a) symmetric and (b) asymmetric rolling showed that AZ31B and ZE10 (ZEK 100) showed minimum cracking and good surface qualities. Arrows shows sheet with cracks and the relatively rough (serrated) surface. 


\subsection{TASK 3: DEVELOP SHEAR ROLLING PROCESS}

The work scope of Task 3 was to develop an understanding of the conditions required to shear roll AZ31B and ZEK100 magnesium alloys to achieve a non-basal texture. Rolling was carried out on two different mills available at ORNL, the Fenn Mill, and the new asymmetric rolling mill co-designed with and built by FATA Hunter, using different rolling conditions and with different sized sheets as explained below.

\subsubsection{Fenn Mill}

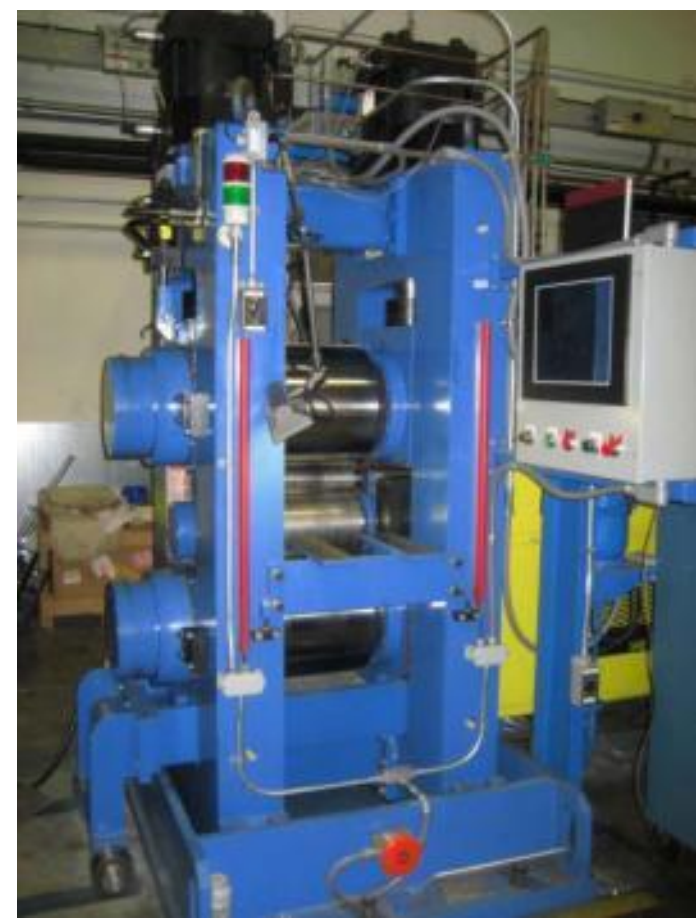

Fig. 5. Fenn mill, available at ORNL.

The Fenn Mill, located at ORNL, is an experimental mill with 11 inch wide rolls (Figure 5). To enable shear rolling on this mill, it was fitted with rolls 9 inches and 3 inches in diameter, giving a circumferential speed ratio of 3:1. It was noticed in very early experiments that a major difference between symmetric rolling and asymmetric rolling was the curl of the sheet as it exited the mill. The curling of sheet happens due to differential deformation across the thickness of the sheet with larger deformation occurring on the side of the sheet in contact with the faster roll. To counteract the curl, a stripper plate arrangement was fitted to the mill, forming a channel through which the curled sheet travelled to restrict the natural tendency for the sheet to curve during exit. The design of the stripper plates was part of a patent application filed with the United States Patent Office by ORNL.

Initial rolling was carried out on the Fenn Mill at ORNL using 2" wide sheet. The first trials on AZ31B and ZEK100 were carried out using the parameters shown in Table 1. Following rolling, the sheets were characterized for their microstructure (in particular qualitatively for grain size and shape), homogeneity of deformation, presence/absence of recrystallization, residual deformation, presence/absence of cracking, and basal texture. Particular emphasis was placed on understanding the feasibility of modifying the basal texture using the asymmetric rolling conditions explored in this part of the study. 
Table 1. Initial parameters employed on the Fenn Mill at ORNL with 3:1 roll speed ratio

\begin{tabular}{|c|c|c|c|}
\hline Alloy & Temperature $\left({ }^{\circ} \mathbf{C}\right)$ & Total Passes & Total Reduction (\%) \\
\hline \multirow{6}{*}{ AZ31B } & \multirow{4}{*}{135} & 1 & 4 \\
\hline & & 1 & 9 \\
\hline & & 1 & 18 \\
\hline & & 5 & 24 \\
\hline & 180 & 4 & 22 \\
\hline & 225 & 7 & 38 \\
\hline \multirow{7}{*}{ ZEK100 } & \multirow{5}{*}{135} & 1 & 6 \\
\hline & & 1 & 13 \\
\hline & & 1 & 24 \\
\hline & & 1 & 38 \\
\hline & & 7 & 42 \\
\hline & 180 & 8 & 43 \\
\hline & 225 & 8 & 46 \\
\hline
\end{tabular}

\subsubsection{Microstructural studies}

Samples of rolled sheet were prepared for analysis using standard metallography techniques. Samples for X-ray texture measurements were polished down to the center-line of the sheet, and finished with a $3 \mu \mathrm{m}$ diamond polish. A 4-axis diffractometer was used with a cobalt $\mathrm{x}$-ray source, and pole figures were measured for the (0002) reflections. EBSD was carried out using a JEOL 6500 Scanning Electron Microscope (SEM). All EBSD maps are shown using inverse pole figure (IPF) coloring with reference to the normal direction of the sheet. In the following sections several qualitative aspects of microstructure in the asymmetrically rolled sheet are discussed along with comparisons between the two alloys studied: AZ31B and ZEK100.

Shear bands were clearly visible in AZ31B samples as shown in Figure 6 indicating inhomogeneity in deformation within the material. In addition, shear bands were more defined at greater reductions, and were visible in AZ31B at all rolling temperatures. At lower temperatures, shear banding also was often related to crack formation during rolling as shown in Figure 6. Shear bands generally formed in opposite directions at each surface, pointing diagonally toward the center and away from the rolling direction. It was also often seen that the slow roll surface produced stronger shear banding, which at larger reductions could stretch across the entire sample. It should be noted from Figure 6 that cracks were occasionally observed at the interface of the shear bands, particularly at large \% reductions and at low temperatures where ductility was quite limited. 


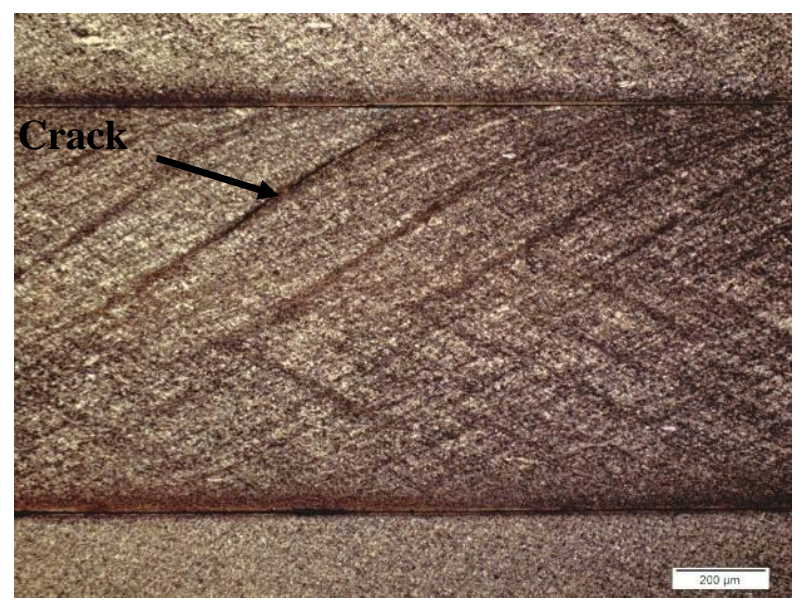

Fig. 6. A crack formed within a shear band in AZ31B asymmetrically rolled with a shear ratio of 3:1 on the Fenn mill at $180^{\circ} \mathrm{C}$ with a total strain of $22 \%$.

Rolling temperature and \% reduction had a clear effect on the microstructure and recrystallization within shear bands. Figure 7 shows the microstructure of AZ31B samples in three different specimen conditions showing that higher temperatures and greater deformation resulted in recrystallization, particularly within the shear bands. No significant grain growth was observed under these rolling conditions.

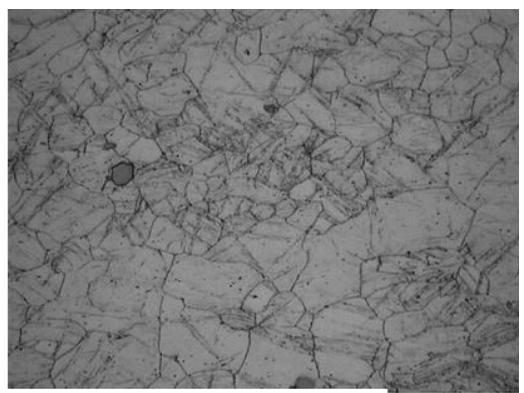

$\stackrel{1000 x}{=} 5 \mu \mathrm{m}$

(a)

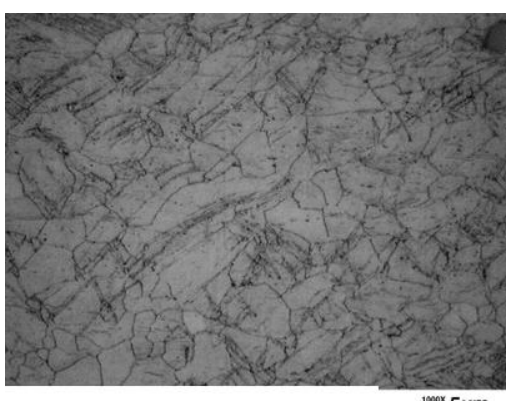

$\frac{1000 x}{20} 5 \mu \mathrm{m}$

(b)

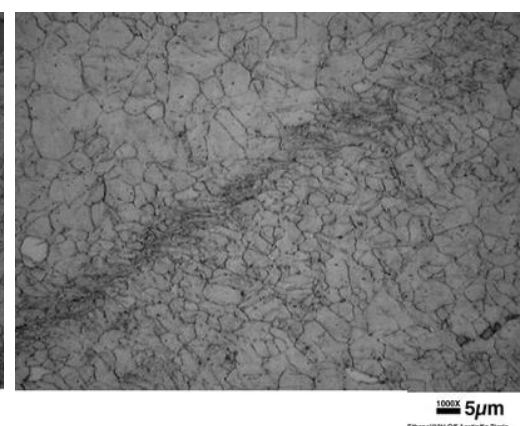

(c)

Fig. 7. Effect of temperature and deformation on recrystallization in asymmetrically rolled $\mathrm{AZ31B}(3: 1)$ (a) $13 \%$ reduction at $135^{\circ} \mathrm{C}$, (b) $18 \%$ at $180^{\circ} \mathrm{C}$, and (c) $38 \%$ at $225^{\circ} \mathrm{C}$.

\subsubsection{Bulk X-ray texture measurements}

$\mathrm{X}$-ray texture measurements were performed on selected specimens at multiple locations through the sheet thickness by sequentially polishing the specimens. Figure 8 shows a typical $\{0002\}$ pole figure from AZ31B in the as-received condition, processed using conventional symmetric rolling. Note that the shape is essentially symmetric with respect to the rolling direction with the peak intensity close to the center of the pole figure. Figure 9 shows the basal pole distribution obtained from the near surface region at the slow roll, the center, and surface near the fast roll on a specimen asymmetrically rolled to a reduction of $38 \%$ at $225^{\circ} \mathrm{C}$ without cracking. Note that there is an elongation in the intensity distribution along the rolling direction and the maximum intensity orientation is tilted away from the sheet normal towards the rolling direction. Also note that the shape changes from the surface to the center of the specimen. These results show that the basal texture of this magnesium alloy sheet can be successfully modified using asymmetric rolling. 


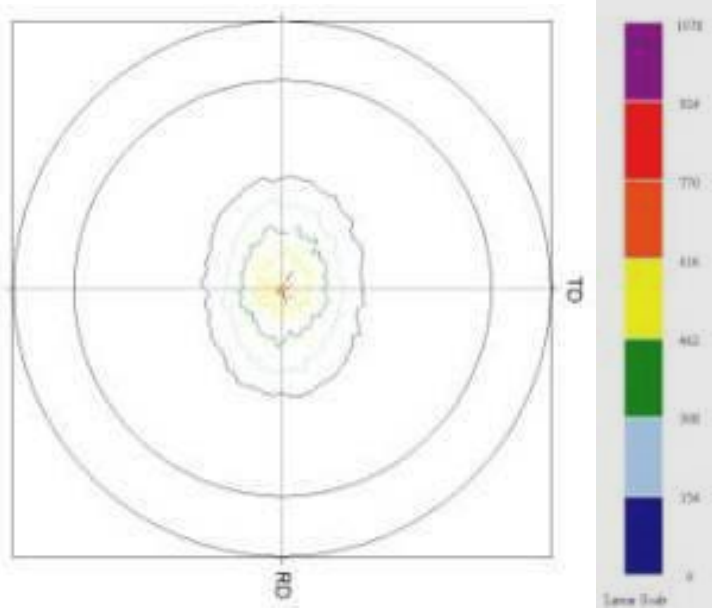

Fig. 8. Typical $\{0002\}$ pole figure from as-received AZ31B. Rolling direction is vertical (Intensity in arbitrary units).
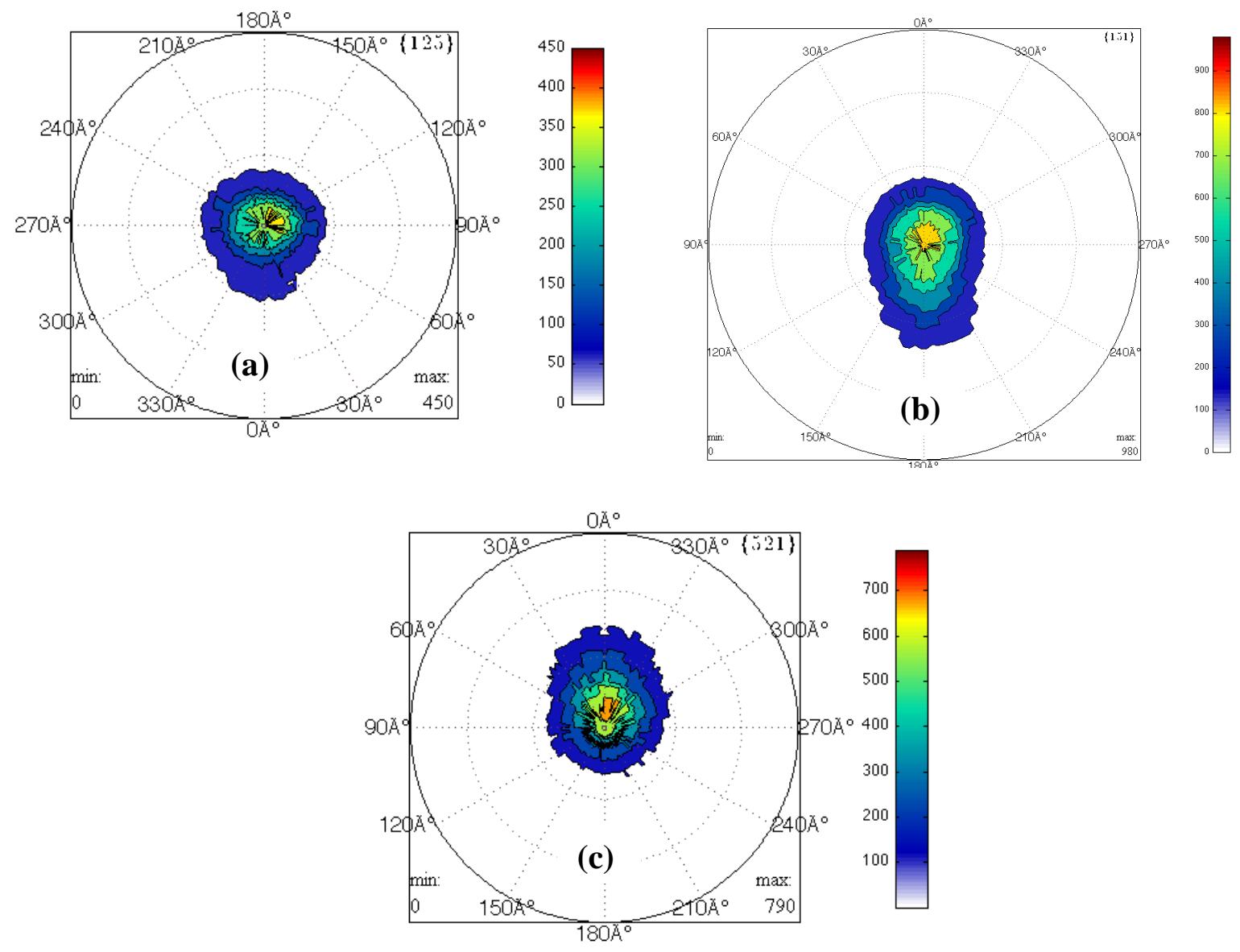

Fig. 9. X-ray texture measurements from a specimen asymmetrically rolled to a reduction of $38 \%$ at $225^{\circ} \mathbf{C}$. $\{0002\}$ pole figures obtained from (a) near the surface in contact with the fast roll, (b) centerline, and (c) near the surface in contact with the slow roll. Rolling direction is vertical. Intensity in arbitrary units. 


\subsubsection{FATA-Hunter Mill}

Eight inch wide strips were rolled on the FATA Hunter mill (see Figure 1) using the conditions shown in Table 2. Reductions of 50\% could not be achieved due to insufficient shape control at the exit side. It was found that slower rolling gave better shape control and surface quality when compared to higher speed asymmetric rolling. Rolled materials were characterized for their microstructure, texture, and in selected cases, formability using the dome testing as described later in section 4 .

Table 2. Rolling conditions for magnesium alloy strips rolled on the FATA Hunter mill

\begin{tabular}{|c|c|c|c|c|}
\hline Alloy & $\begin{array}{c}\text { Roll Temperature } \\
\qquad\left({ }^{\circ} \mathbf{C}\right)\end{array}$ & $\begin{array}{c}\text { Metal } \\
\text { Temperature }\left({ }^{\circ} \mathbf{C}\right)\end{array}$ & Roll Speeds (rpm) & Reduction (\%) \\
\hline \multirow{12}{*}{ AZ31B } & \multirow{12}{*}{175} & \multirow{12}{*}{175} & \multirow{6}{*}{$300 / 300$} & 5 \\
\hline & & & & 7 \\
\hline & & & & 9 \\
\hline & & & & 10 \\
\hline & & & & 13 \\
\hline & & & & 27.6 \\
\hline & & & \multirow{4}{*}{$300 / 412.5$} & 3 \\
\hline & & & & 6 \\
\hline & & & & 7 \\
\hline & & & & 8 \\
\hline & & & \multirow{2}{*}{$220 / 604$} & 7.5 \\
\hline & & & & 15 \\
\hline \multirow{10}{*}{ AZ31B } & \multirow{9}{*}{200} & \multirow{9}{*}{200} & \multirow{4}{*}{$300 / 300$} & 8 \\
\hline & & & & 15 \\
\hline & & & & 22 \\
\hline & & & & 42 \\
\hline & & & $300 / 405$ & 12 \\
\hline & & & \multirow{2}{*}{$200 / 270$} & 15 \\
\hline & & & & 30 \\
\hline & & & \multirow{2}{*}{$200 / 600$} & 16 \\
\hline & & & & 41 \\
\hline & 280 & 300 & $300 / 300$ & 10 \\
\hline \multirow{6}{*}{ ZEK100 } & \multirow{6}{*}{200} & \multirow{6}{*}{200} & \multirow{2}{*}{$300 / 300$} & 14 \\
\hline & & & & 24 \\
\hline & & & \multirow{2}{*}{$200 / 270$} & 15 \\
\hline & & & & 32 \\
\hline & & & \multirow{2}{*}{$200 / 600$} & 12 \\
\hline & & & & 33 \\
\hline
\end{tabular}




\subsubsection{Microstructural analysis}

Figure 10 shows the microstructures of AZ31B sheets rolled at $200^{\circ} \mathrm{C}$ : a) symmetrically rolled at $25 \%$ reduction, b) asymmetrically rolled by $25 \%$ at $1: 1.35$ shear ratio, and c) asymmetrically rolled by $40 \%$ at a ratio of 3:1. Note that the asymmetrically rolled specimens shown in Figures 10(b) and (c) show a recrystallized grain structure which seems to have considerably coarsened, particularly in the specimen shown in Figure 10(c) which was subject to a $40 \%$ reduction at $200^{\circ} \mathrm{C}$.

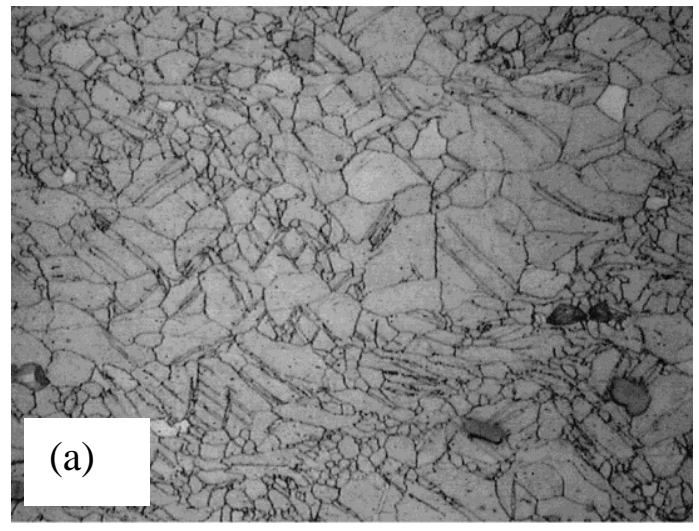

11-1806-04 Mg-RP6L
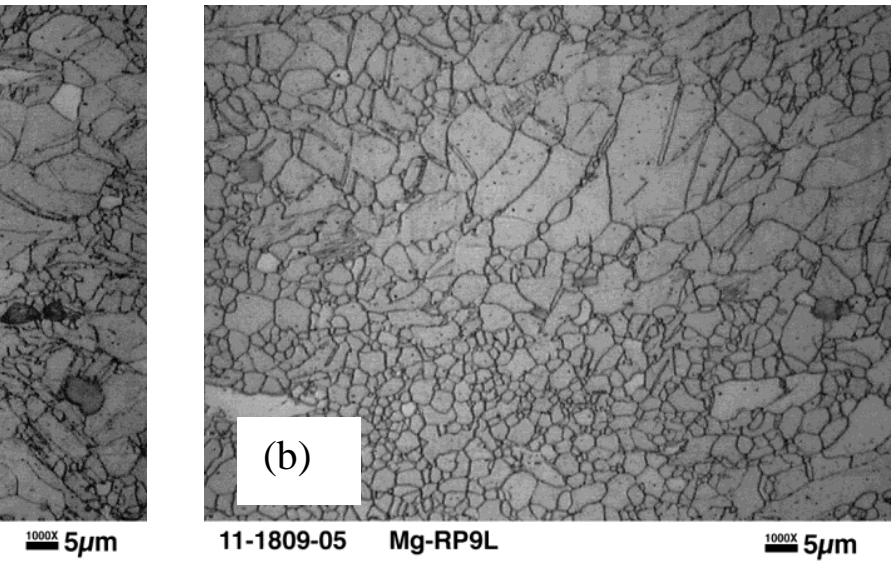

11-1809-05 Mg-RP9L

1000x $5 \mu \mathrm{m}$

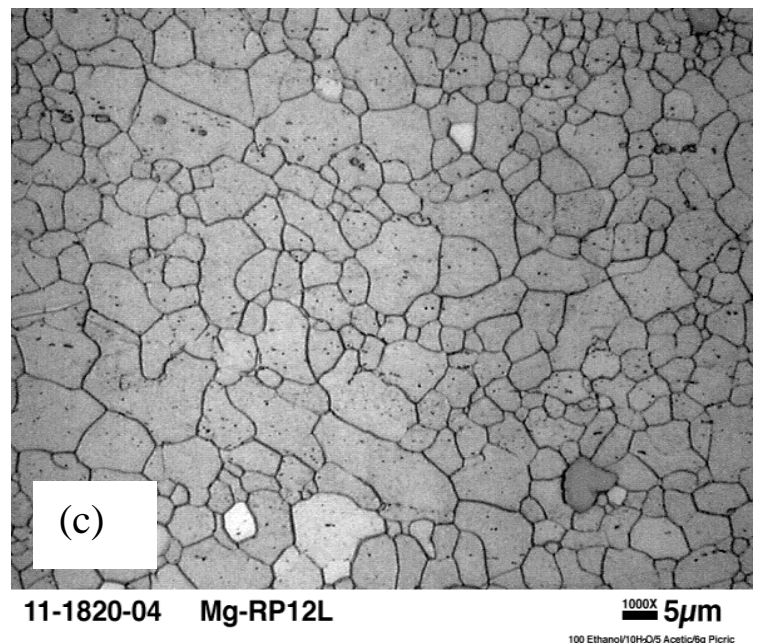

Fig. 10 Microstructure of AZ31B specimens rolled at $200^{\circ} \mathrm{C}$ (a) symmetrically rolled at $25 \%$ reduction (b) asymmetrically rolled by $25 \%$ at $1: 1.35$ shear ratio, and (c) asymmetrically rolled by $40 \%$ at a ratio of $3: 1$

\subsubsection{Bulk X-ray texture measurements}

Figure 11 shows the $\{0002\}$ pole figures obtained from the centerline of three specimens: a baseline AZ31B prior to shear rolling, AZ31B symmetrically rolled at $200^{\circ} \mathrm{C}, 25 \%$ reduction, and a specimen asymmetrically rolled by $25 \%$ at a $1: 1.35$ shear ratio and a temperature of $200^{\circ} \mathrm{C}$. Note again that the asymmetrically rolled specimen shows asymmetry in the distribution of basal pole intensities in the rolling direction accompanied by a tilting of the poles resulting in the maximum intensity being away from the direction of the sheet normal. Thus asymmetric rolling clearly results in the modification of the basal texture and again demonstrates the fact that asymmetric rolling can modify the basal texture of magnesium alloy sheets. 


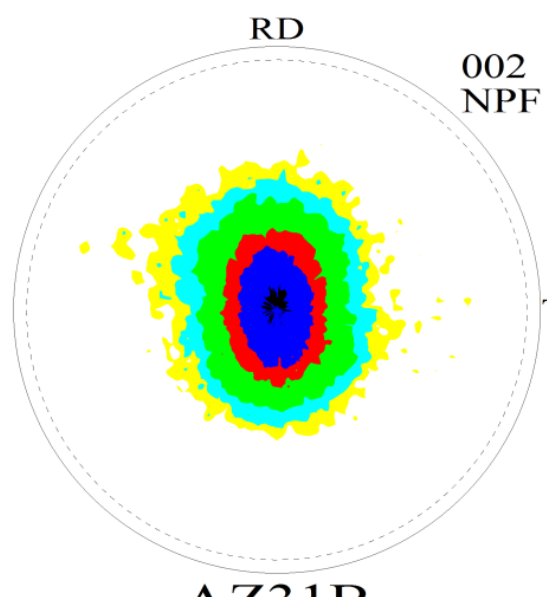

AZ31B
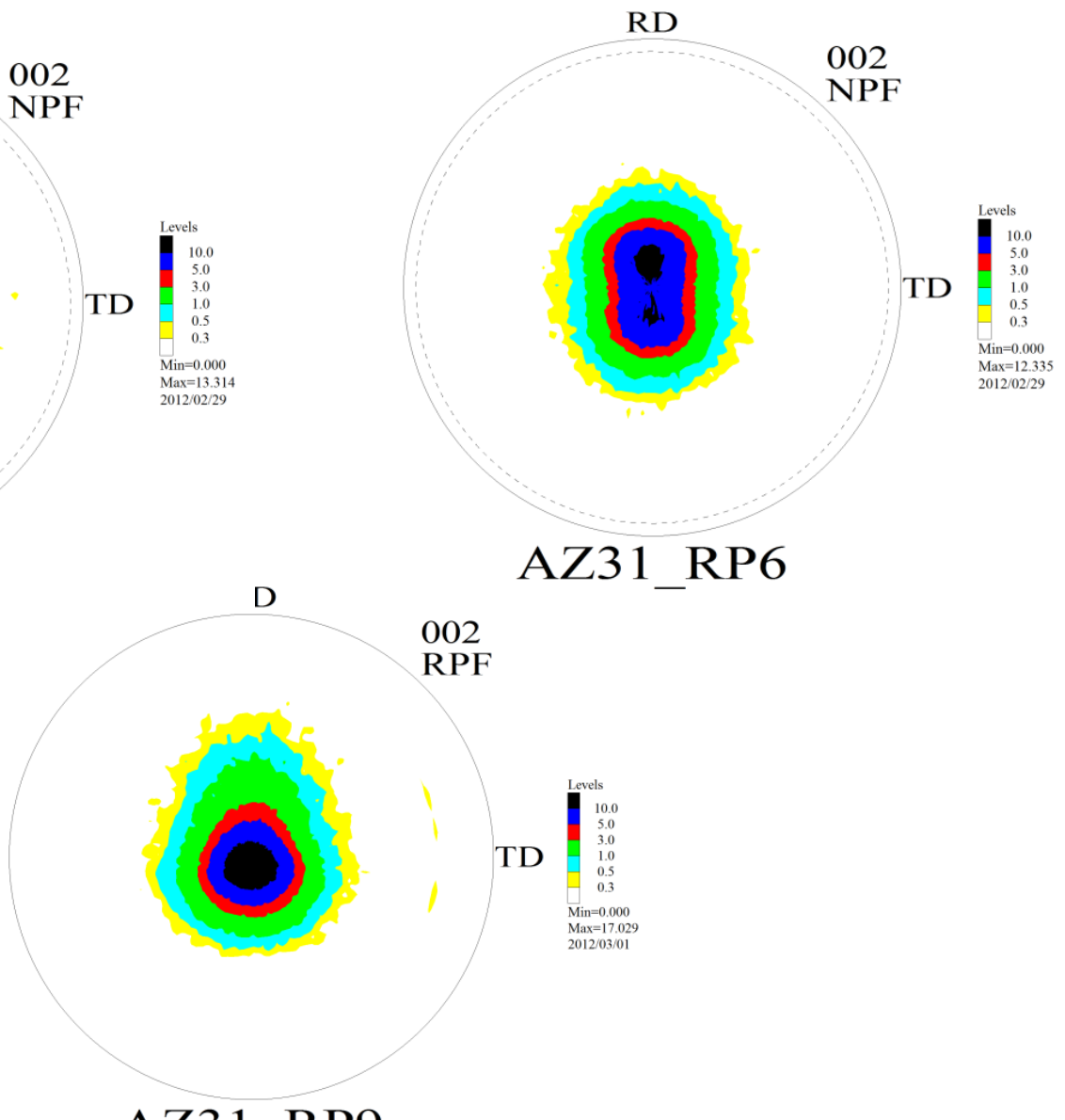

AZ31_RP6

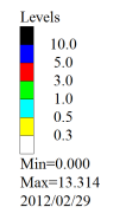

AZ31_RP9

Fig. 11. X-ray texture measurements from (a) a specimen prior to asymmetric rolling, (b) symmetrically rolled at $200^{\circ} \mathrm{C}, 25 \%$ reduction, and (c) asymmetrically rolled by $25 \%$ at $1: 1.35$ shear ratio at a temperature of $200^{\circ} \mathrm{C}$. Rolling direction is vertical. Intensity shown is normalized to intensity from a randomly oriented specimen.

\subsection{TASK 4: DEMONSTRATE SHEAR ROLLING IN AN INDUSTRIAL PROCESS ENVIRONMENT}

The scope of Task 4 was to demonstrate the feasibility of shear rolling magnesium alloy sheet in an industrial environment and in particular to demonstrate the rolling of wider sheets on an industrial scale mill. This was carried out at MENA using '8-Mill' described earlier. Table 3 shows the matrix of rolling trials carried out on the 8-Mill with nominal temperatures and reductions. Both symmetric (1:1) roll speeds and asymmetric rolling was performed on this mill to understand the differences between the microstructures and textures of sheet that were rolled using these different processing conditions. Samples were used in formability testing as described in Section 4 and 36 inch wide sheets were also rolled to prove that shear rolling could be scaled up to an industrial sized process as described in section 5 . 
Table 3. Matrix of parameters used for rolling sheet using the 8-mill at MENA.

\begin{tabular}{|c|c|c|c|}
\hline Alloy & Temperature $\left({ }^{\circ} \mathbf{C}\right)$ & Total Passes & Total Reduction (\%) \\
\hline \multirow{9}{*}{ AZ31B } & 200 & 1 & 10 \\
\hline & 200 & 1 & 25 \\
\hline & 200 & 1 & 50 \\
\hline & 250 & 1 & 10 \\
\hline & 250 & 1 & 25 \\
\hline & 250 & 1 & 50 \\
\hline & 350 & 1 & 25 \\
\hline & 425 & 1 & 10 \\
\hline & 425 & 1 & 50 \\
\hline \multirow{9}{*}{ ZEK100 } & 200 & 1 & 10 \\
\hline & 200 & 1 & 25 \\
\hline & 200 & 1 & 50 \\
\hline & 250 & 1 & 10 \\
\hline & 250 & 1 & 25 \\
\hline & 250 & 1 & 50 \\
\hline & 350 & 1 & 25 \\
\hline & 425 & 1 & 10 \\
\hline & 425 & 1 & 50 \\
\hline
\end{tabular}

It was encouraging to note that both AZ31B and ZEK100 sheets rolled using single pass reductions of 10 and $25 \%$ produced good quality sheets, with no edge cracking and a relatively flat profile, see Figure 12 (left). At large reductions per pass (50\% reduction), the shape control was much worse and a center buckle developed during the rolling of all sheets, especially at lower temperatures, see Figure 12 (right). The AZ31B alloy also showed significant edge cracking at the lower temperatures when compared to ZEK100.

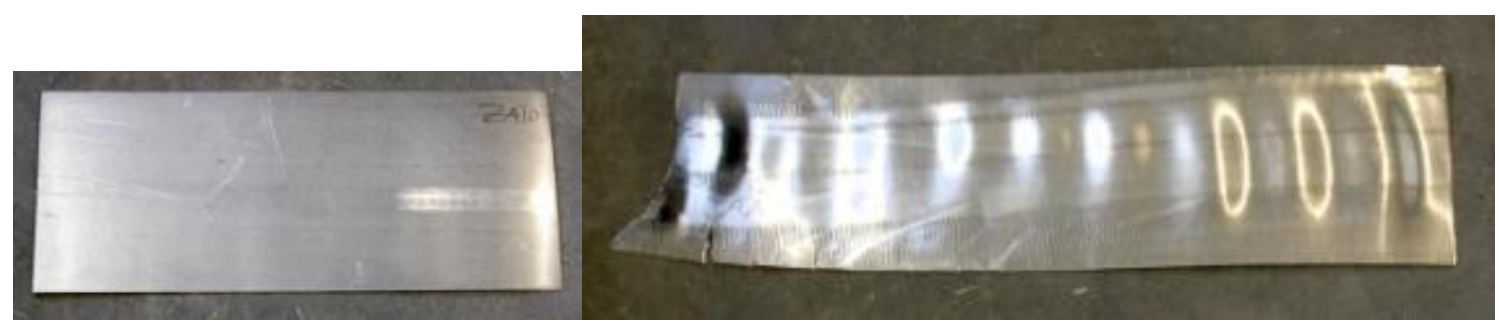

Fig. 12. Effect of processing condition on quality of sheet produced using the 8-mill. The photograph on the left shows $\mathrm{ZEK} 100$ rolled at $425^{\circ} \mathrm{C}$ with $10 \%$ reduction. The photograph on the right shows AZ31B rolled at $200^{\circ} \mathrm{C}$ with $50 \%$ reduction.

Several practical difficulties and anomalies were encountered during the process development for the 8-mill. For example, it was observed that the curling of sheet was not always predictable. Although the sheet was expected to curl away from the fast roll due to that surface encountering greater deformation, this effect was not always observed. The exact cause of the absence of curling is unknown, but two 
explanations are possible. The first is that the sheet was simply sticking to the upper roll and was being bent after it had exited the roll gap, inducing an opposite curvature into the sheet. The second is that there was a difference in friction between the two rolls. At the very start of rolling this was unlikely since the rolls were ground to exactly the same finish. However, it is possible that after several passes were carried out, a build-up of magnesium and magnesium oxide occurred on the rolls modifying the surface finish and hence the friction coefficient. The amount of build-up is likely to be different on the upper and lower rolls due to the difference in the speeds of the two rolls and the contact length. This would change the friction coefficient between the roll and the material, which would alter the forces on the sheet, causing a variation of the total shear forces. It was also observed that the rolling of the narrow sheet and shape control was facilitated by the presence of the stripper plate.

The next task was to develop the asymmetric rolling process for wider sheets (36") of AZ31B and ZEK100. When scaling up to this wider sheet, more process difficulties were encountered. The main complications were with the shape and finish of the metal. These difficulties were again related to the direction of curling. As explained earlier, it was anticipated that the material would increase in length on the side of the fast roll, and thus curl downwards. This behavior had been observed in previous trials, and therefore the stripper plates were designed such that the lower plate was positioned very close to the roll to ensure the material did not wrap around the roll. However, it was found during rolling on 8-Mill that the material did not behave entirely as expected. In many cases, the material curved upwards. This caused problems with the stripper plates and certain sheets came into contact with the plate edges when they exited the mill. It was found that the positioning of the stripper plates was critical in controlling the sheet exit process in the shear rolling mill. The stripper plates needed to be shaped carefully and adjusted to fit less than 0.008 inches from the roll surface.

Adding lubrication/cooling to the process greatly helped to decrease the shape problems and eliminate chatter. The narrow strips were rolled with no lubrication and thus the first wide sheets were rolled exactly the same way. It was thought that lack of lubrication would result in higher shear stresses on the material, due to higher friction. However, after a few sheets had been rolled, the material started to 'chatter' very badly through the roll bite, with alternating regions of sticking and slipping, as a result of pickup on the rolls. This produced a very uneven surface, which was expected to give inconsistent amounts of shear deformation. For this reason, lubrication was used for the remainder of rolling. While there may have been more slipping at the roll surface, and consequently less shear forces applied to the metal, the overall quality was much better and more consistent. Shape control was also improved by the application of lubricant due to cooling of the rolls. Figure 13 shows a typical example of the type of problem that was encountered during the rolling process. The leading edge of the sheet is shown in the foreground. A clear line between good, flat material at the start and poorly shaped/warped material at the end was clearly visible. The initial good section was approximately one revolution of the rolls, and it is thought that heating from the rolls was responsible for the change in shape. The use of coolant minimized these issues by cooling the rolls during processing. It was also found that large reductions exacerbated the problems and it was not possible to deform greater than $25 \%$ on the wide material, limiting the process window available. Hence thirty-six inch wide sheets of AZ31B and ZEK100 were asymmetrically rolled nominally at $250^{\circ} \mathrm{C}$ with only a $10 \%$ reduction. These sheets were used for forming automotive components as described later in the report. 


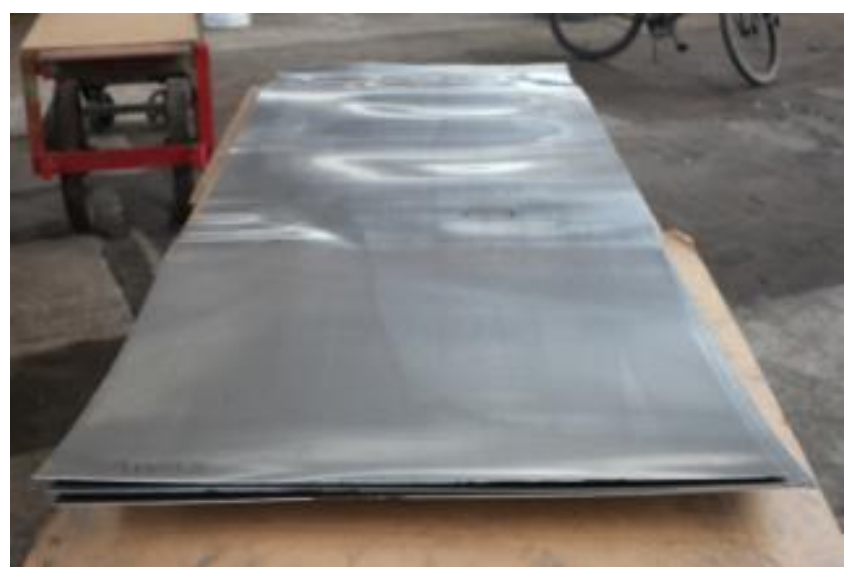

Fig. 13. Photograph of rolled sheets showing the difference in shape control along the length.

It was realized that due to unpredictable friction conditions related to the temperature and the surface roughness that varied during the rolling process, there was a need to understand the amount of shear actually imparted to the sheet during asymmetric rolling. Two strips of AZ31B containing drilled holes were asymmetrically rolled on the 8 -mill at $370{ }^{\circ} \mathrm{C}$, one by a $10 \%$ and the other by a $50 \%$ reduction. The sample rolled by a $10 \%$ reduction in thickness showed a small curl downward at the beginning, and an upward curl towards the end of the sheet whereas the sheet rolled to a $50 \%$ reduction showed a very strong upward curl along the full length. Although the sheet rolled by a 10\% reduction showed a change in shape during rolling, the holes were found to be consistently angled in the same direction in both areas. Sections through the holes are shown in Figure 14 and Figure 15. It can be seen that in both samples, the hole was tilted in the direction that would be expected from a large (fast) roll on top, despite the curl of the sheet being opposite and that the tilting is larger in the sample reduced to a greater reduction in thickness.

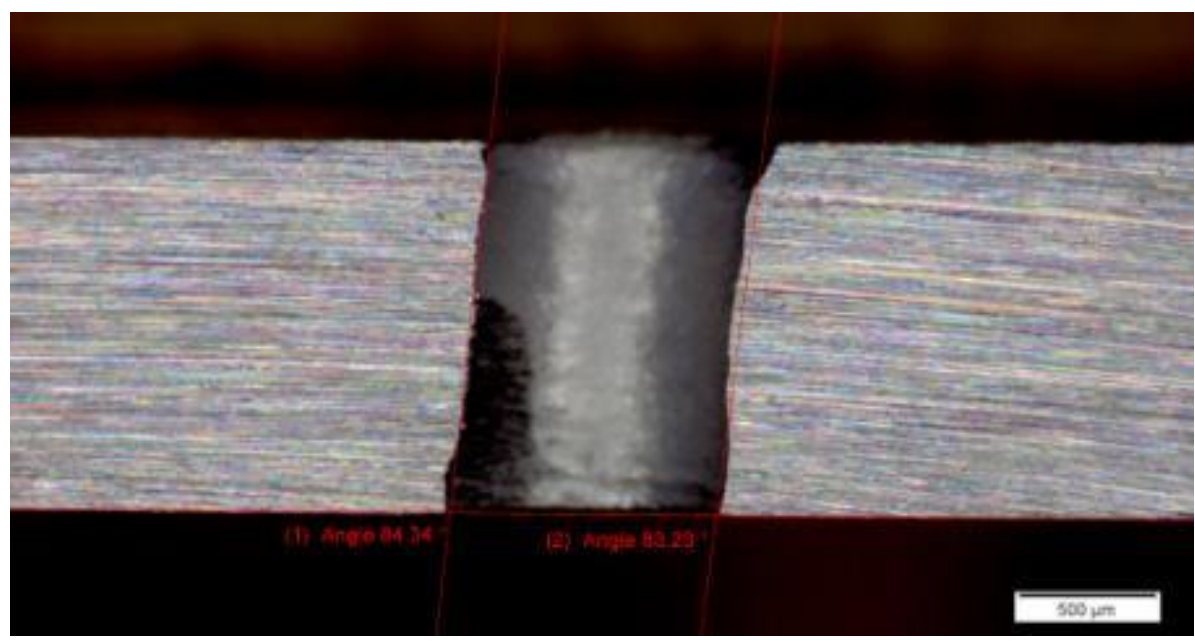

Fig. 14. Section through a drilled hole in a sample deformed asymmetrically at $370^{\circ} \mathrm{C}$ with $10 \%$ reduction. The top surface was in contact with the fast roll and the bottom surface with the slow roll. The rolling direction was left to right. 


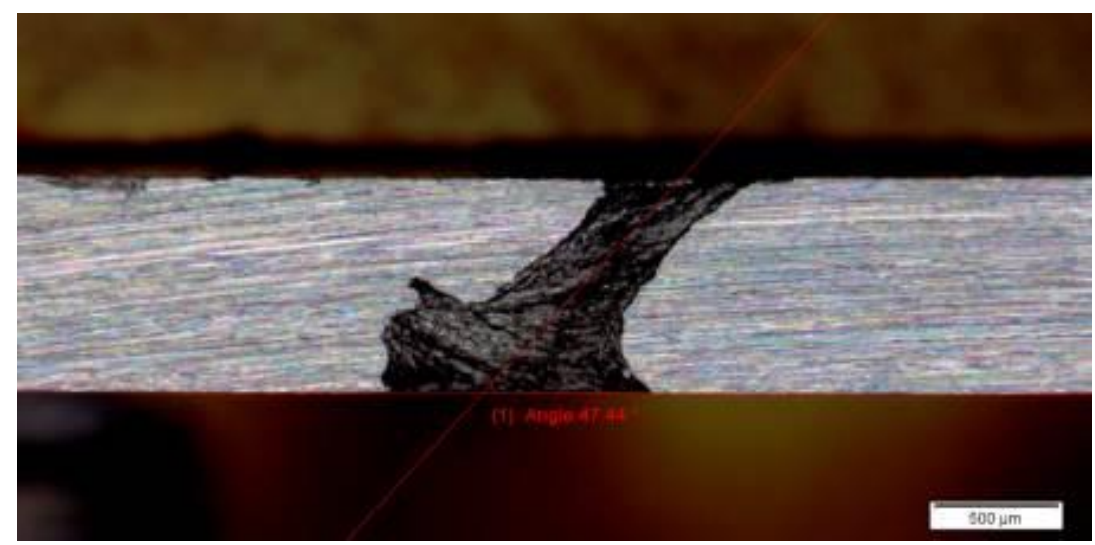

Fig. 15. Section through a drilled hole in a sample deformed asymmetrically at $370^{\circ} \mathrm{C}$ with $50 \%$ reduction. The top surface was in contact with the fast roll and the bottom surface with the slow roll. The rolling direction was left to right.

In summary, it should be noted that although difficulties were encountered during the scale-up of the asymmetric rolling process, both AZ31B and ZEK100 sheets were successfully rolled using the modified 8-Mill and, as explained later, components were fabricated using the rolled sheet.

\subsubsection{Microstructural Analysis}

Figure 16 shows the microstructure of the starting sheet material prior to rolling. The microstructures were fully recrystallized and homogeneous through the full thickness. It was found that the rate of grain growth in AZ31B was faster than that of ZEK100 at high temperatures. Thus the initial grain sizes of the AZ31B and ZEK100 varied strongly as a function of rolling temperature since these sheets were preheated before rolling. This grain growth and the grain size difference was particular significant in sheets that were asymmetrically rolled due to the following reason. In symmetric rolling, all samples were simply heated to the required rolling temperature and then rolled. However, all samples rolled asymmetrically were heated to $425^{\circ} \mathrm{C}$ and then cooled to the requisite rolling temperature. This preheat step caused more extensive grain growth in the feedstock for asymmetric rolling than symmetric rolling. Thus, the initial grain sizes before rolling cannot be directly compared between the symmetric and asymmetric rolling conditions even for the same alloy and nominally the same rolling temperature. This discrepancy was particularly serious in AZ31B due to the higher rate of grain growth when compared to ZEK100, where the differences were only slight.

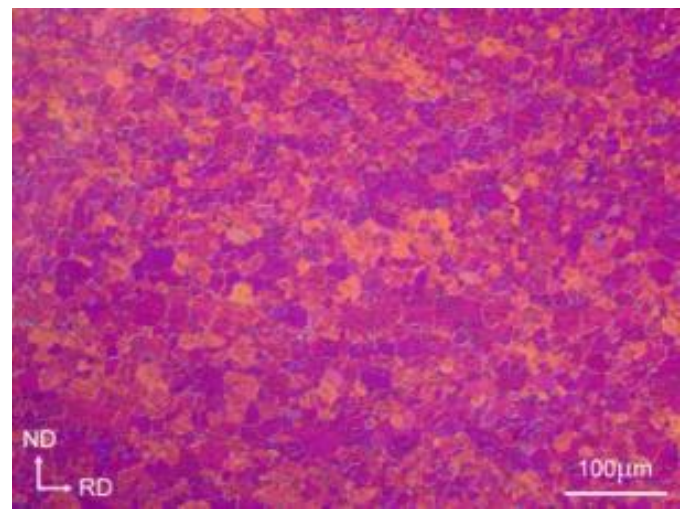

(a)

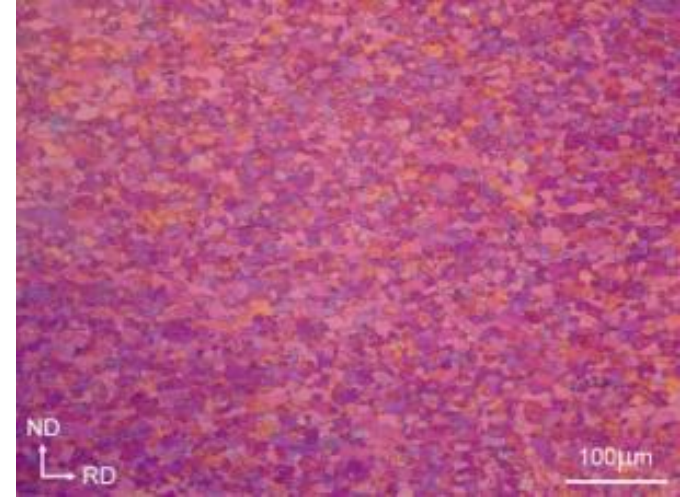

(b)

Fig. 16. Optical micrographs of AZ31B (left) and ZEK100 (right) feed stock materials. 
The microstructure following rolling (see Figures 17 and 18) contained the same basic features at all conditions, with little difference observed between the microstructures of the sheets rolled symmetrically and asymmetrically at the same temperature. The pre-existing grains were flattened and elongated by the compressive forces during rolling in both asymmetric and symmetric modes. Shear bands were formed in all samples and the grains within these shear bands were extensively refined. The samples rolled to $50 \%$ reduction showed much more extensive grain refinement when compared to the samples rolled by a $10 \%$ reduction in thickness. The samples rolled at $250^{\circ} \mathrm{C}$ are shown here as examples but similar differences were observed at all rolling temperatures, with the additional observation that more grain growth occurred at higher rolling preheat temperatures.

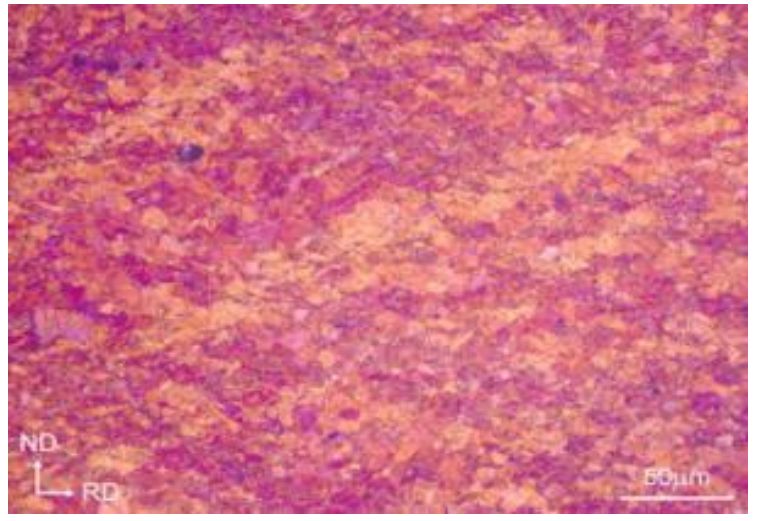

(a)

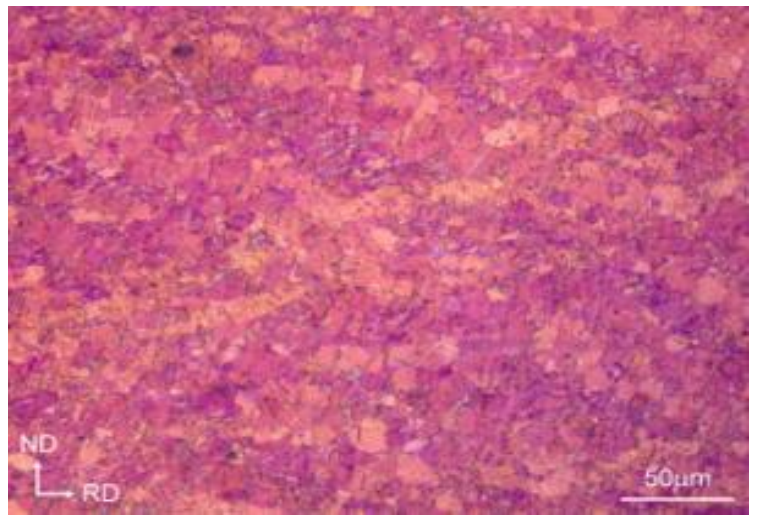

(b)

Fig. 17. AZ31B rolled at $250^{\circ} \mathrm{C}$ with $10 \%$ reduction on 8 -Mill in (a) symmetric mode and (b) asymmetric mode (right).

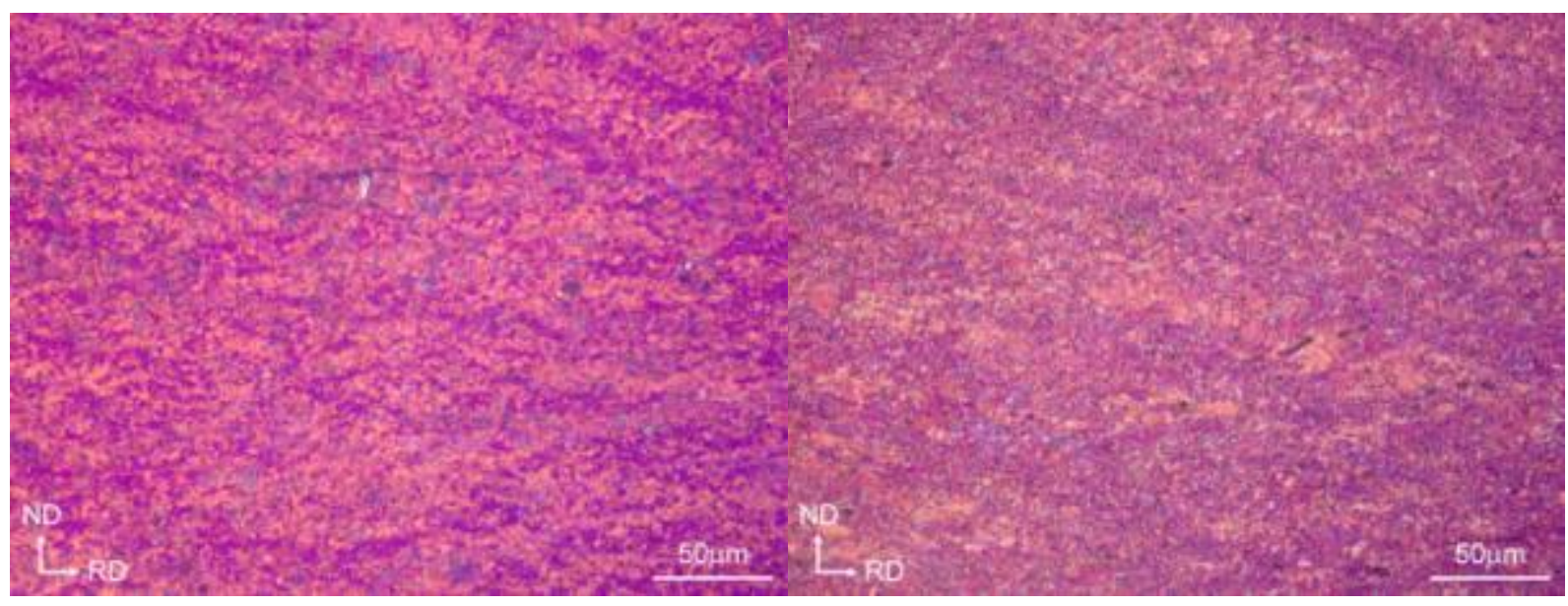

(a)

(b)

Fig. 18. AZ31B rolled at $250^{\circ} \mathrm{C}$ with $50 \%$ reduction on 8-Mill in (a) symmetric mode and (b) asymmetric mode.

The ZEK100 microstructure (see Figures19 and 20) showed similar behavior to AZ31B. Again, grains were elongated due to the rolling process and some shear banding occurred. With $50 \%$ reductions, it appeared that shear bands had consumed the majority of the material. The work carried out within the shear bands is, by definition, greater than that in regions outside these shear bands, and thus it appears that recrystallization was also much more active within this region. Recrystallization caused a large decrease in the grain size within this region, which is generally expected to improve formability. 


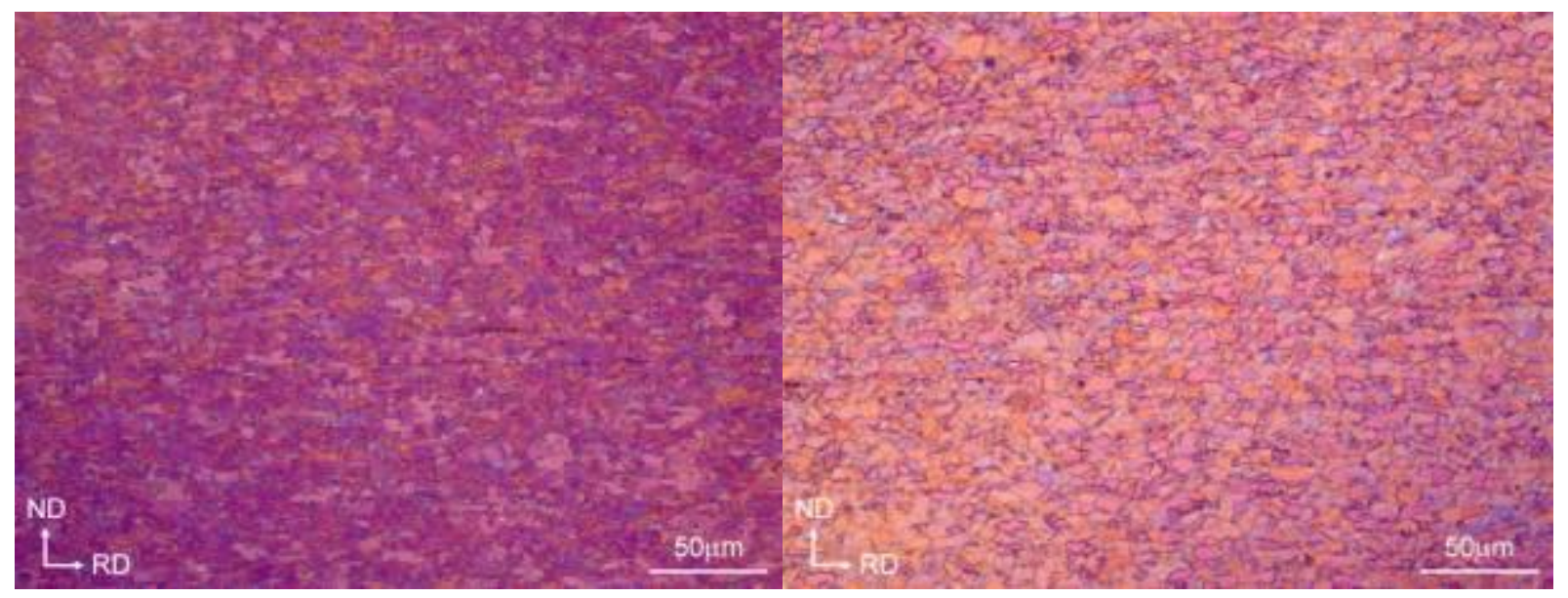

(a)

(b)

Fig. 19. ZEK100 rolled at $250^{\circ} \mathrm{C}$ with $10 \%$ reduction on 8 mill in symmetric mode (left) and asymmetric mode (right).

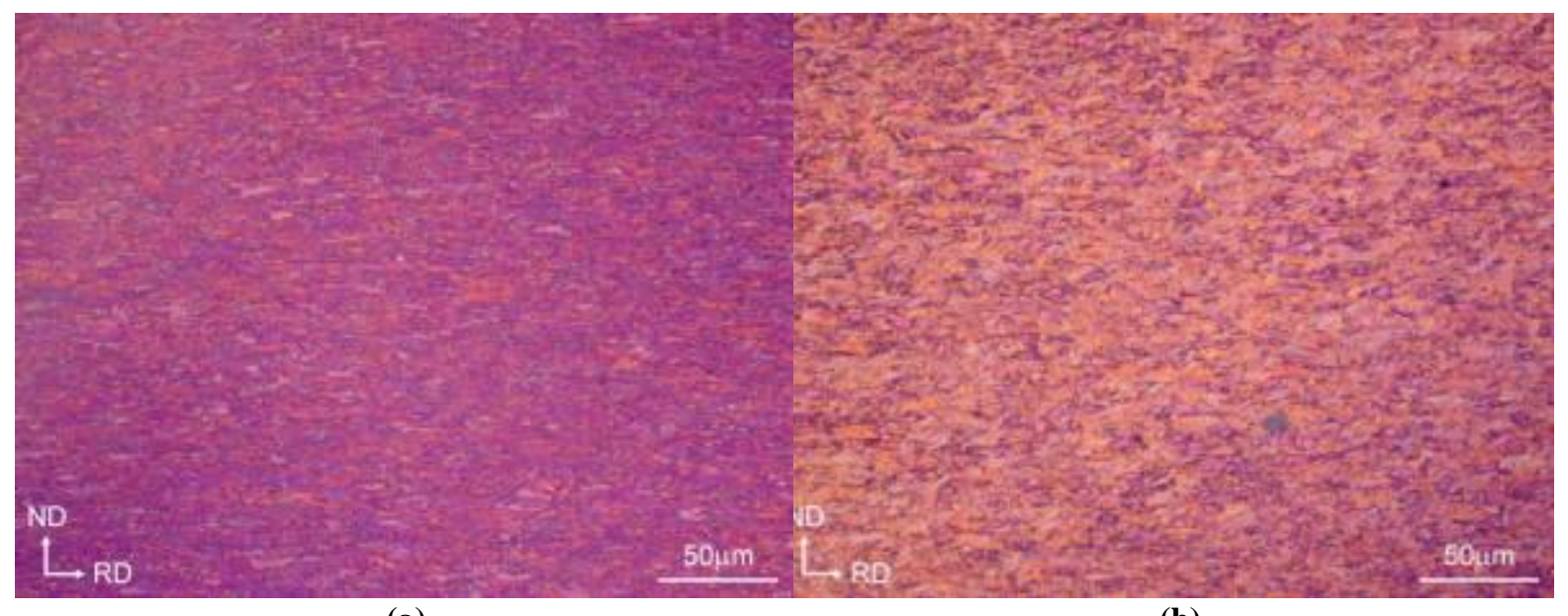

(a)

(b)

Fig. 20. ZEK100 rolled at $250^{\circ} \mathrm{C}$ with $50 \%$ reduction on 8 mill in symmetric mode (left) and asymmetric mode (right).

The microstructures of shear rolled sheets were mostly homogeneous through the full thickness, with the exception of a very small region at each surface. This region was generally less than $100 \mu \mathrm{m}$ thick and contained finer grains, (Figure 21). In the AZ31B sample shown in Figure 21 the layer of fine grains was only present at the slow roll surface. In the ZEK100 sample, the layers were much thicker and were present at both surfaces. The layer at the fast roll surface was wider but a stronger grain refinement effect was seen at the slow roll surface. It is surmised that dynamic recrystallization resulted in the formation of small grains leading to grain size refinement during shear rolling with greater strains generally resulting in earlier onset and more extensive recrystallization. These results suggest that the surface layers experienced higher strains than the bulk of the sheets. It also suggests that the slow roll surface underwent a larger local strain than the fast roll surface. This region would be expected to play a greater role as the thickness of the rolled sheet decreases. 


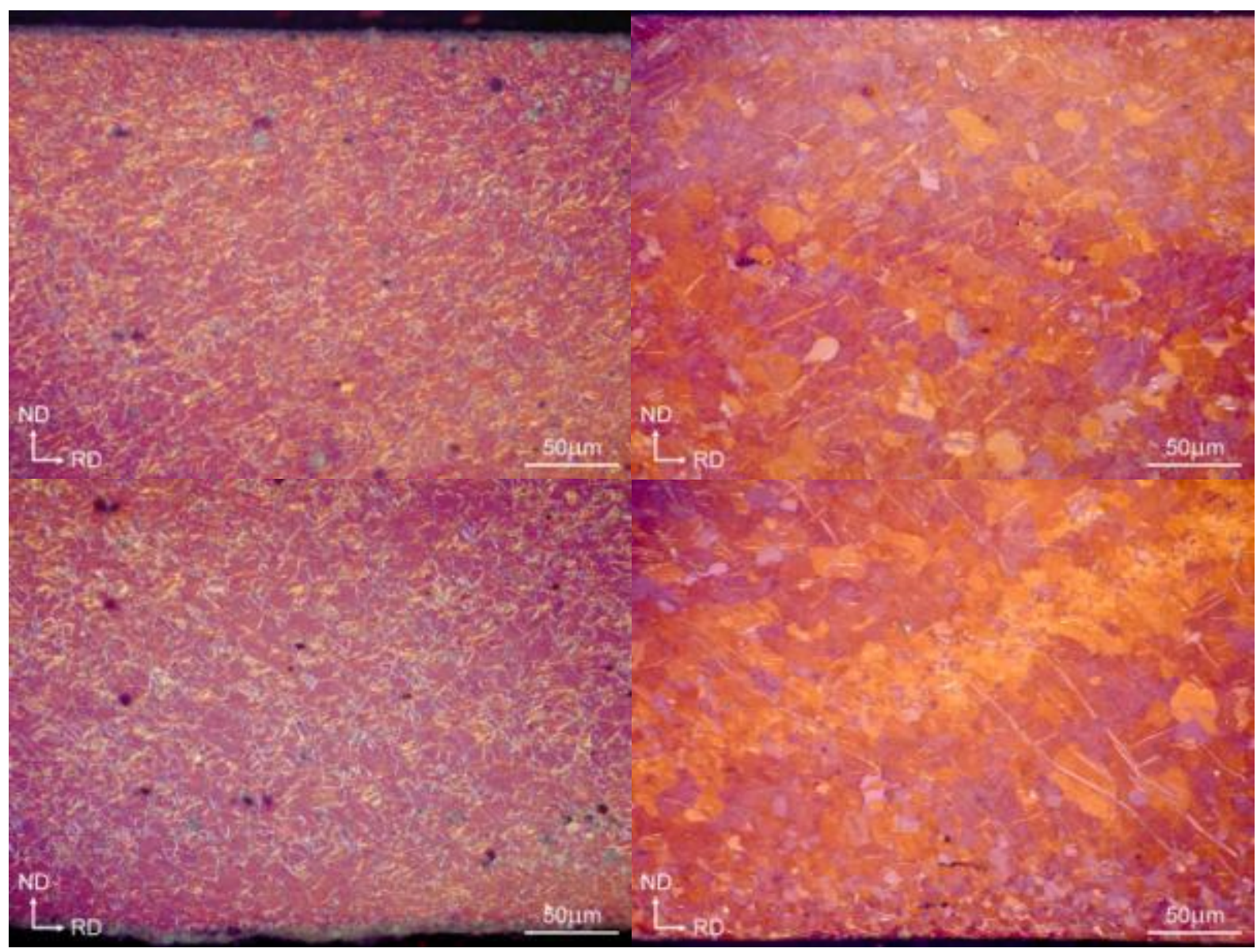

Fig. 21. AZ31B (left) and ZEK100 (right) shear rolled in a multipass schedule at $225^{\circ} \mathrm{C}$ to a total strain of approximately $50 \%$ on the Fenn mill showing the microstructural variation close to the slow roll (top) and fast roll (bottom) surface.

\subsubsection{Bulk X-ray Texture Measurements}

Since modification of the basal texture is critical to improving the formability, the texture at the centerline was evaluated in all rolled samples. Figure 22 shows the texture of the AZ31B feedstock materials used for rolling experiments on the 8-Mill (initial sheet texture) for reference. The $\{0002\}$ pole intensity was centered strongly on the normal direction in the sheet with a wider spread towards the rolling direction than the transverse direction (elliptical in shape). 


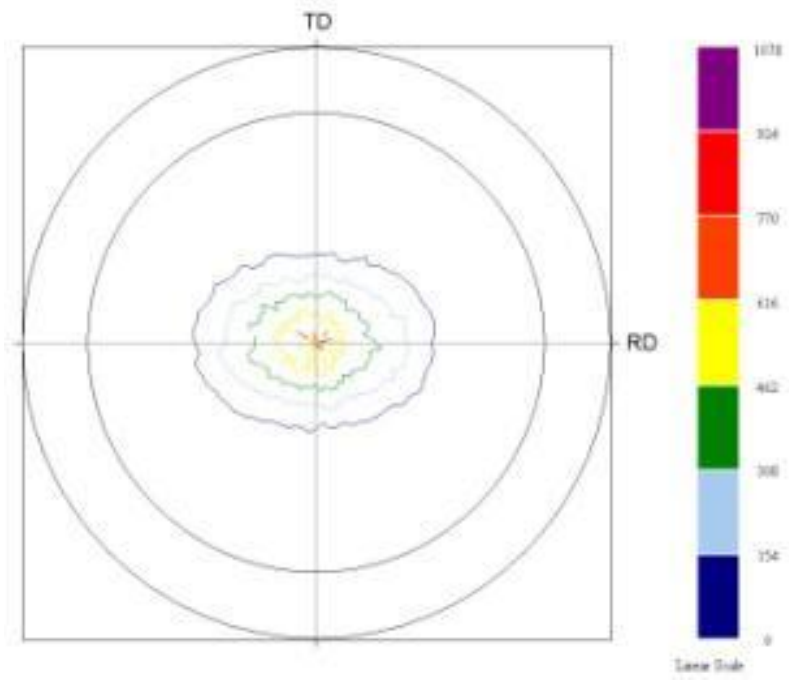

Fig. 22. XRD 0002 pole figure for AZ31B feedstock (rolling direction is horizontal). Intensity shown in arbitrary units.

Figures 23-26 show the texture after rolling in both symmetric and asymmetric modes, at temperatures of $250^{\circ} \mathrm{C}$ and $425^{\circ} \mathrm{C}$ and reductions of $10 \%$ and $50 \%$. A split in the basal texture is often seen in symmetrically rolled magnesium alloy sheet and is particularly apparent in the textures of AZ31B shown in Figure 23 (a), which is from a sheet rolled by a reduction of $10 \%$ at $250^{\circ} \mathrm{C}$, in Figure 24 (a) which is from a sheet rolled by a reduction of $50 \%$ at $250^{\circ} \mathrm{C}$, and in Figure 26 (a) which is from sheet rolled by a reduction of $50 \%$ at $425^{\circ} \mathrm{C}$. In contrast, Figures 23 (b), 24 (b) and 26(b) show that asymmetric rolling induces a tilt in the pole figure away from the sheet normal and towards the rolling direction. The differences between the symmetric and asymmetric rolling textures seem to be the lowest in sheets rolled at $425^{\circ} \mathrm{C}$ to a reduction of $10 \%$ perhaps due to extensive dynamic recrystallization at this temperature. These differences are again amplified in the sheet rolled at $425^{\circ} \mathrm{C}$ to a 50\% reduction in thickness. From these results it can be concluded that asymmetric rolling can induce modification of the basal texture but this observation can vary depending on the temperature and amount of reduction achieved during the pass.

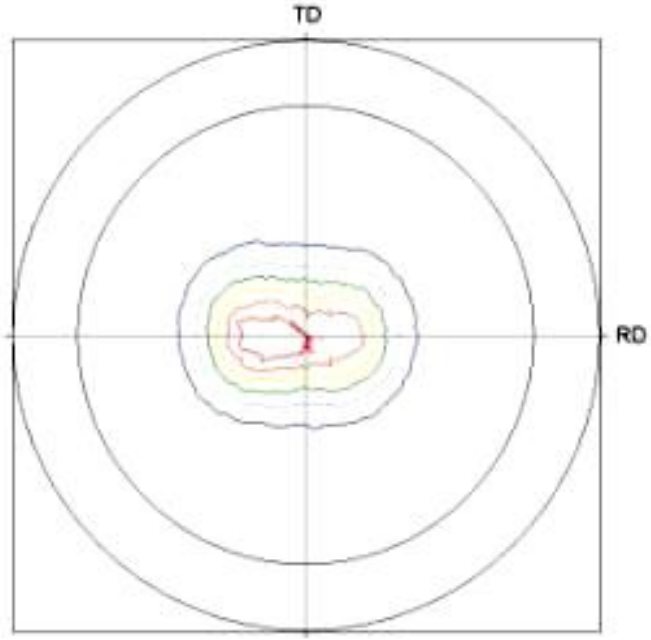

(a)

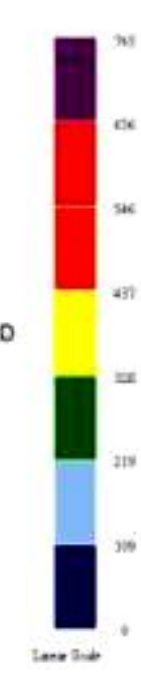

Linenting

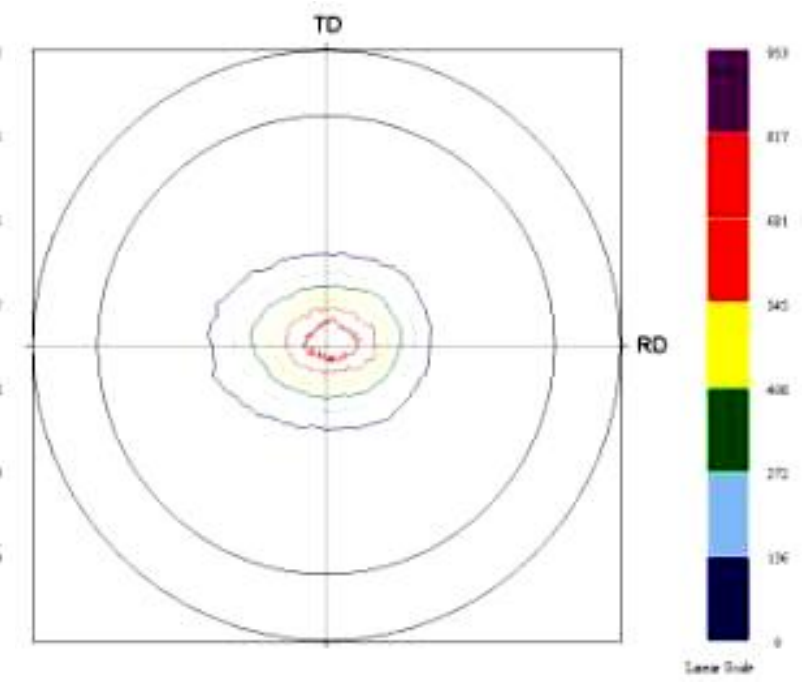

(b)

Fig. 23. XRD 0002 pole figures for $\mathrm{AZ31B}$ rolled at $250^{\circ} \mathrm{C}$ with $10 \%$ reduction in (a) symmetric mode and (b) asymmetric mode. Intensity shown in arbitrary units. 


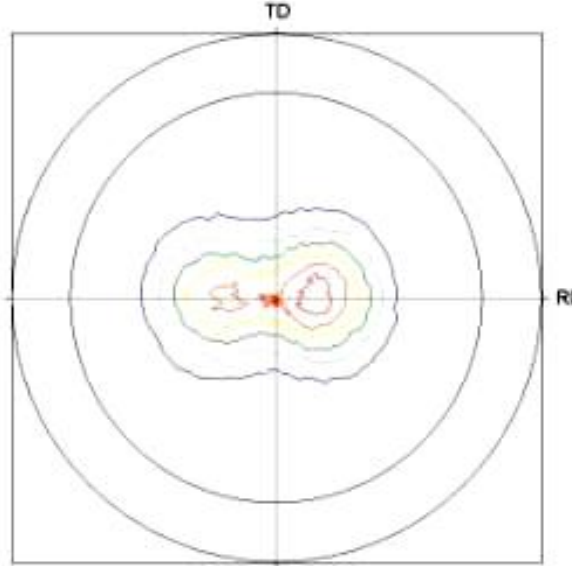

(a)
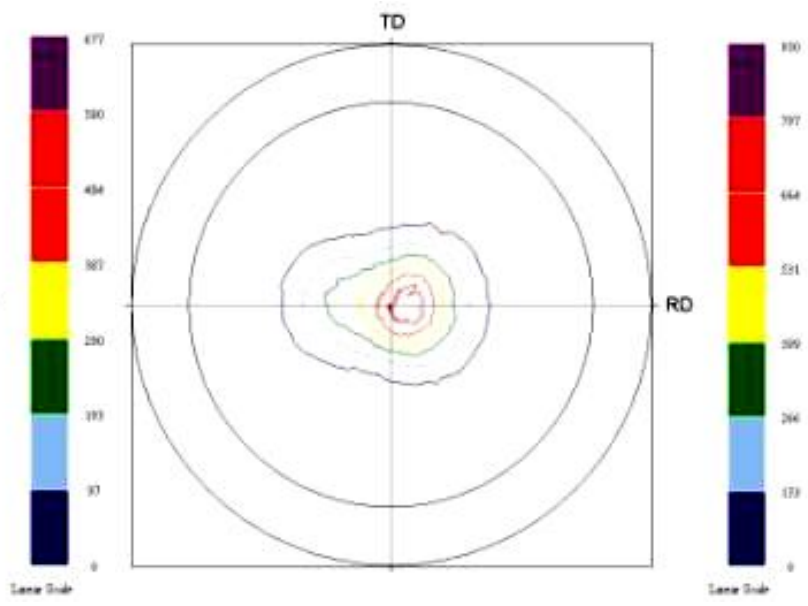

(b)

Fig. 24. XRD 0002 pole figures for AZ31B rolled at $250^{\circ} \mathrm{C}$ with $50 \%$ reduction in (a) symmetric mode and (b) asymmetric mode (right). Intensity shown in arbitrary units.

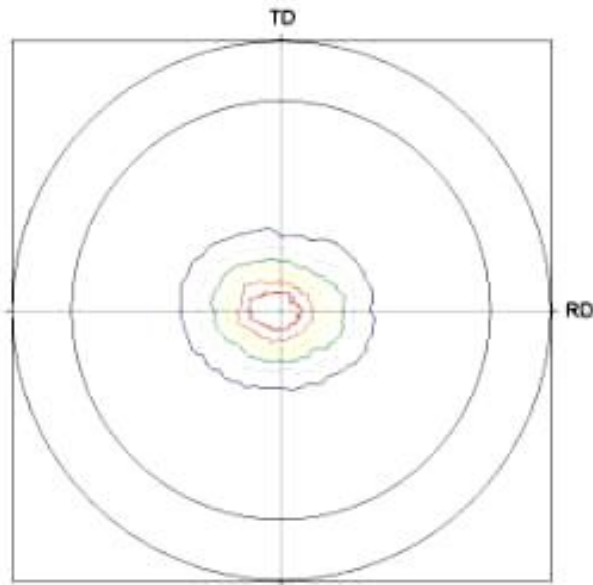

(a)
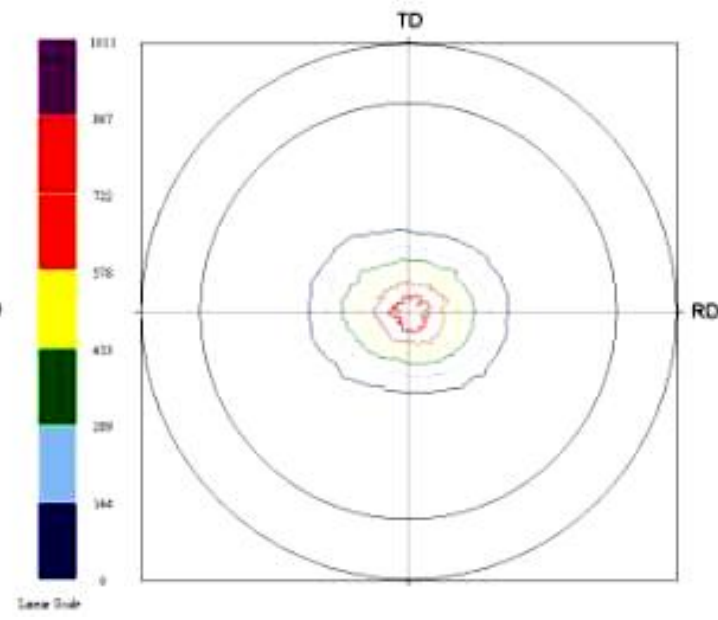

(b)

Fig. 25. XRD 0002 pole figures for AZ31B rolled at $425^{\circ} \mathrm{C}$ with $10 \%$ reduction in (a) symmetric mode and (b) asymmetric mode (right). Intensity shown in arbitrary units. 


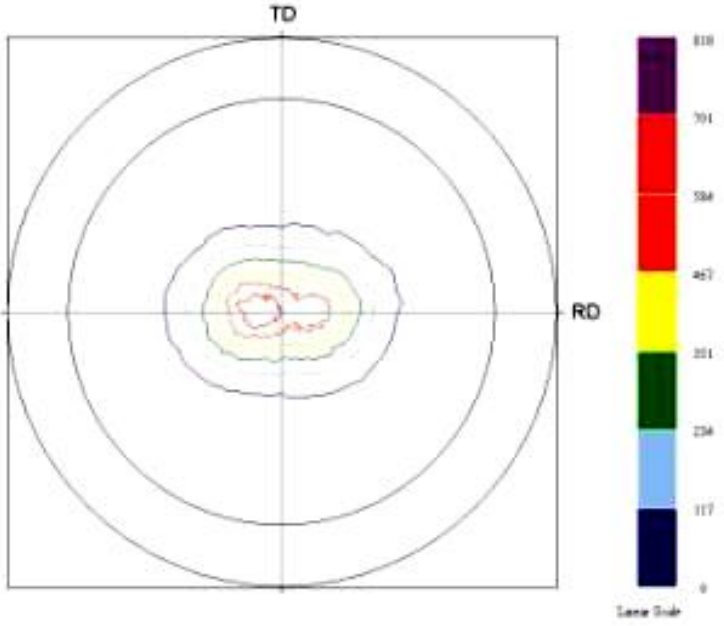

(a)

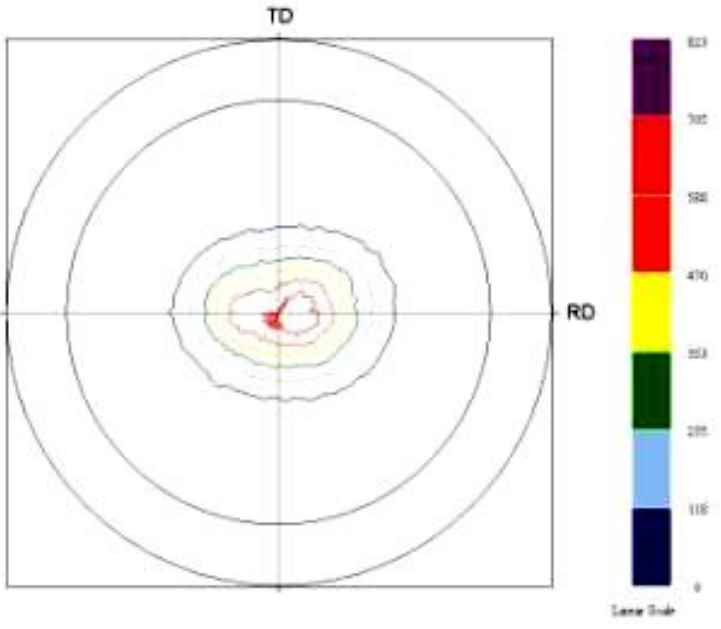

(b)

Fig. 26. XRD 0002 pole figures for AZ31B rolled at $425^{\circ} \mathrm{C}$ with $50 \%$ reduction in (a) symmetric mode and (b) asymmetric mode (right). Intensity shown in arbitrary units.

Figure 27 shows the texture of the starting ZEK100 feedstock. It can be seen that this was very different from that of AZ31B feedstock as shown in Figure 22. The ZEK100 showed a split of the basal pole towards the transverse direction, and generally weaker intensities, a general texture known as the 'rare earth texture,' which is generally related to improved formability ${ }^{3}$. Figures $28-31$ show the textures of sheets rolled symmetrically and asymmetrically at temperatures of $250^{\circ} \mathrm{C}$ and $425^{\circ} \mathrm{C}$ and reductions of $10 \%$ and $50 \%$. During rolling, the basal planes rotated along the rolling direction to result in split in the distribution of basal planes along the rolling direction, known as a 'standard split basal texture'. Deformation to a greater strain, especially at the lower temperatures, led to an almost fully standard split basal texture. Rolling in asymmetric mode caused only a small tilt with $10 \%$ reduction; however it significantly rotates the entire texture towards the rolling direction with $50 \%$ reductions. The maximum intensity of the pole figures is generally lower in the asymmetrically rolled samples, indicating that the overall texture is weaker. Thus, it has been clearly demonstrated that modification of the initial texture can be achieved in both AZ31B and ZEK100 (primarily tilting of texture away from the sheet normal) through asymmetric rolling.

3 Jan Bohlen et al., "The texture and anisotropy of magnesium-zinc-rare earth alloy sheets," Acta Materialia, Vol. 56, No. 7, April 2007, p.2101-2112. 


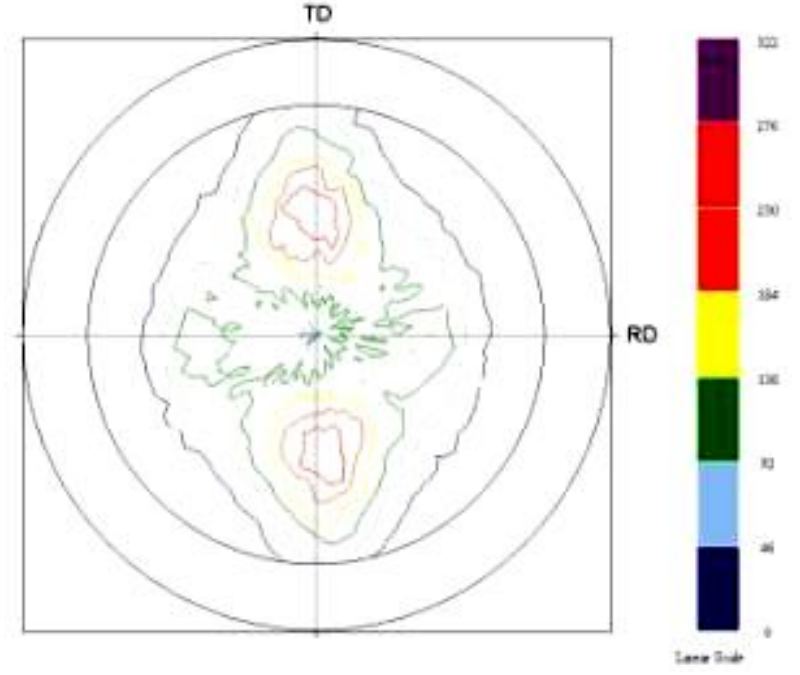

Fig. 27. XRD 0002 pole figure for ZEK100 feedstock. Intensity shown in arbitrary units.

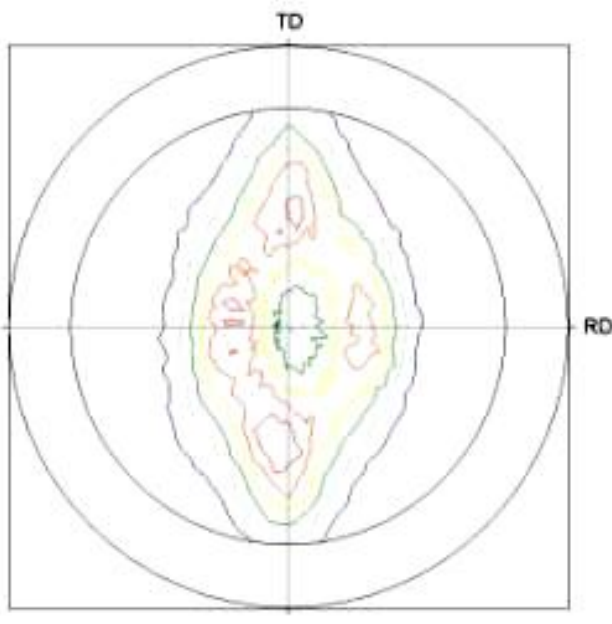

(a)

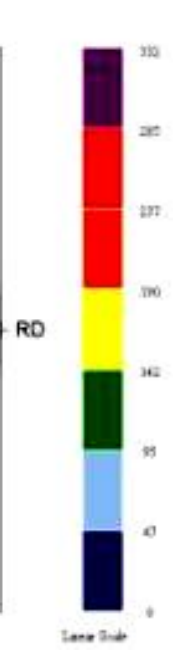

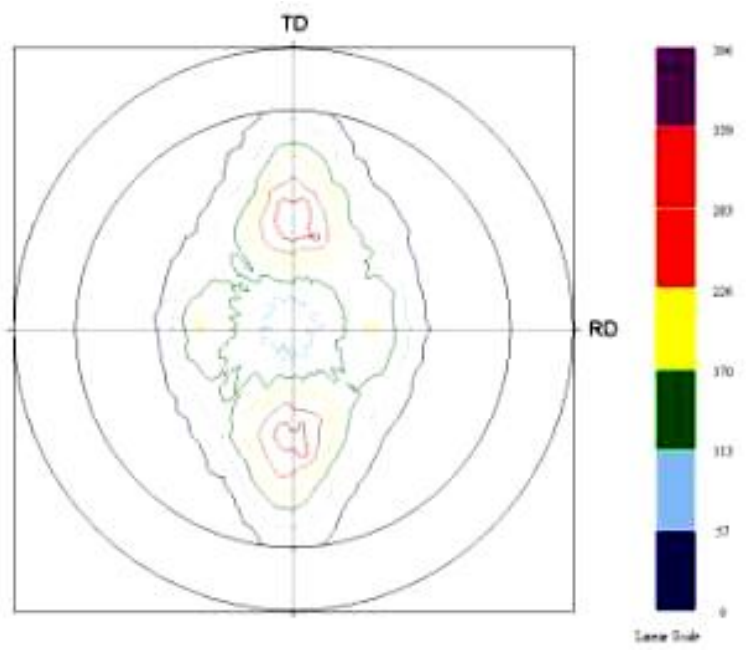

(b)

Fig. 28. XRD 0002 pole figures for $\mathrm{ZEK} 100$ rolled at $250^{\circ} \mathrm{C}$ with $10 \%$ reduction in (a) symmetric mode and (b) asymmetric mode. Intensity shown in arbitrary units. 


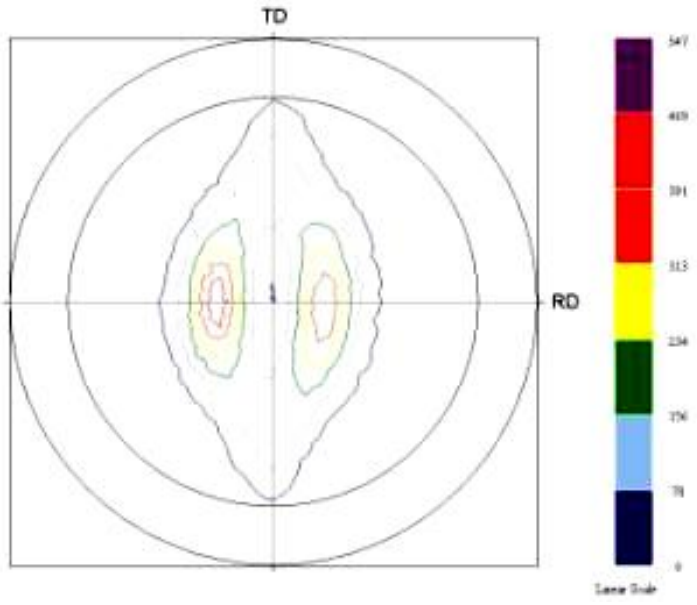

(a)

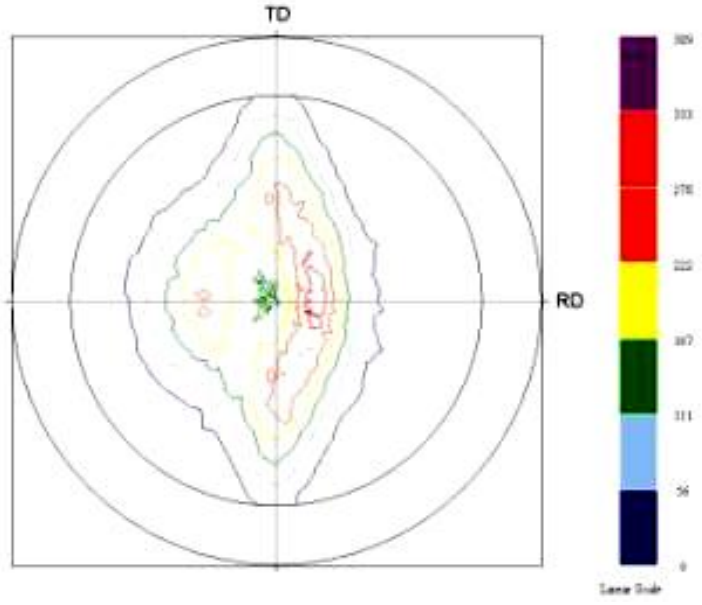

(b)

Fig. 29. XRD 0002 pole figures for $\mathrm{ZEK} 100$ rolled at $250^{\circ} \mathrm{C}$ with $50 \%$ reduction in (a) asymmetric mode and (b) asymmetric mode. Intensity shown in arbitrary units.

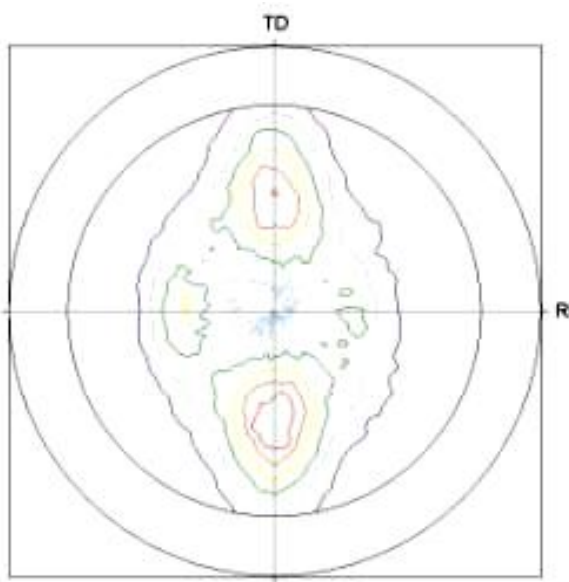

(a)
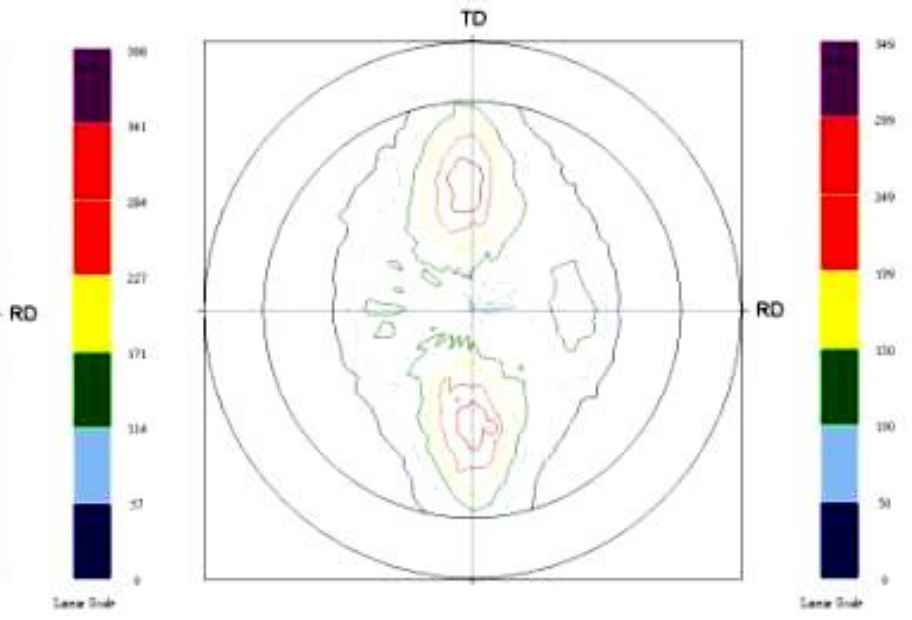

(b)

Fig. 30. XRD 0002 pole figures for ZEK100 rolled at $425^{\circ} \mathrm{C}$ with $10 \%$ reduction in (a) symmetric mode and (b) asymmetric mode. Intensity shown in arbitrary units. 


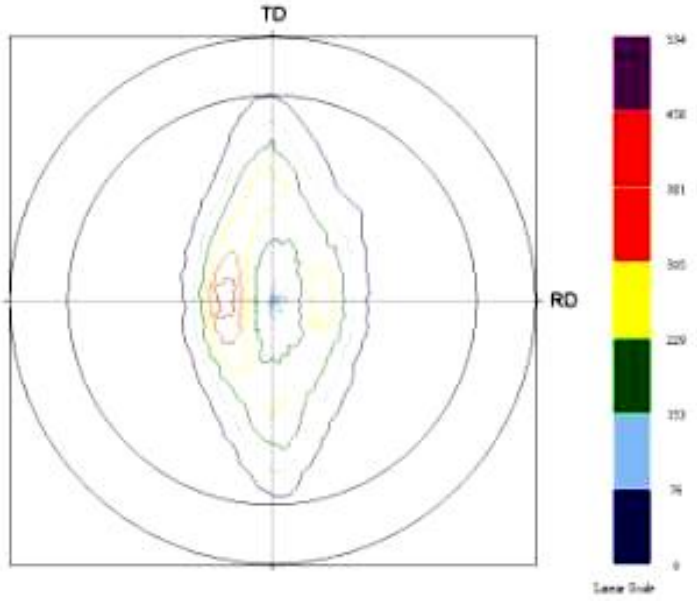

(a)

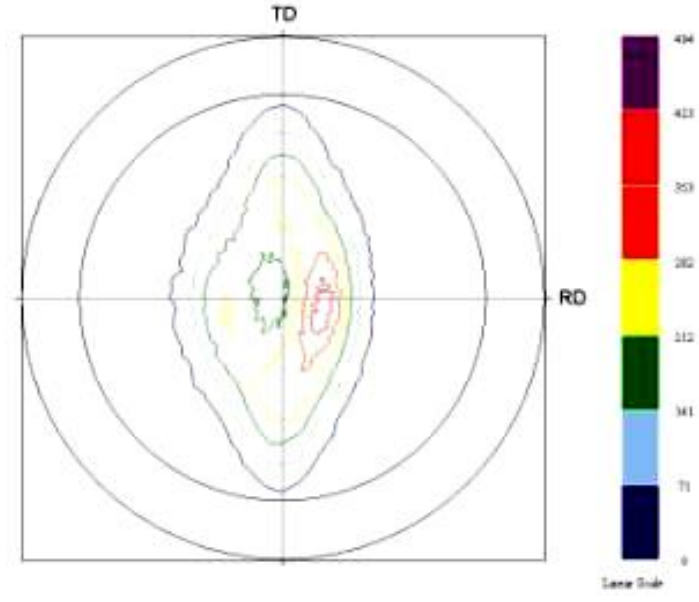

(b)

Fig. 31. XRD 0002 pole figures for ZEK100 rolled at $425^{\circ} \mathrm{C}$ with $50 \%$ reduction in symmetric mode (left) and asymmetric mode (right). Intensity shown in arbitrary units.

\subsubsection{EBSD Analysis of Microstructure}

Limited EBSD work was performed on cross-sections of the samples to relate the texture observed at small scales to the $\mathrm{x}$-ray texture measurements performed on a large area of the specimen. Figure 32 shows an EBSD map on the centerline of an AZ31B sheet that was rolled symmetrically at $250^{\circ} \mathrm{C}$ with $10 \%$ reduction. Figure 33 shows the orientations of the grains corresponding to the colors. The majority of grains in this map are colored red, indicating that there was a very strong basal texture. It should be recalled that results from x-ray texture measurements shown in Figure 23(a) suggest a splitbasal texture for the same condition. The grains were mostly the same size as in the feedstock, and many were slightly elongated, indicating that they were original, non-recrystallized grains. There were also some much smaller grains around the original grain boundaries, most likely due to dynamic recrystallization during rolling.

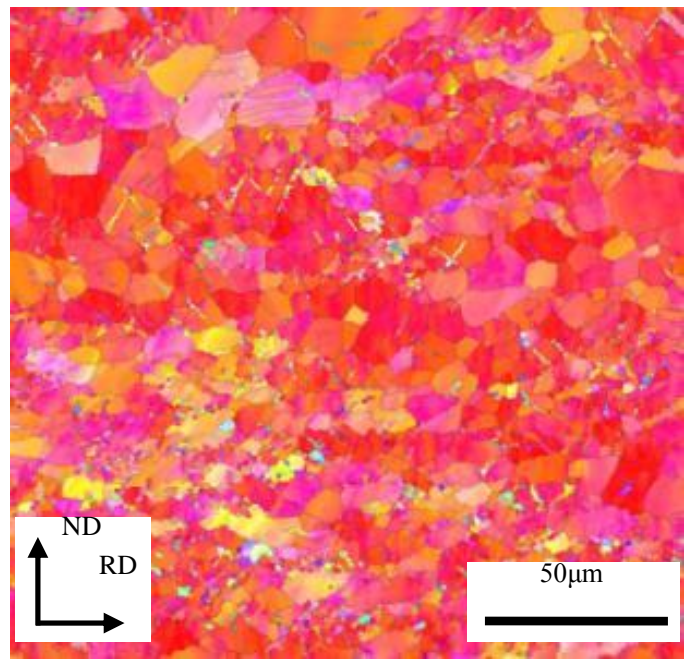

Fig. 32. EBSD map (IPF coloring) of an AZ31B sheet rolled symmetrically at $250^{\circ} \mathrm{C}$ with $10 \%$ reduction (map taken at the sheet centerline.) 


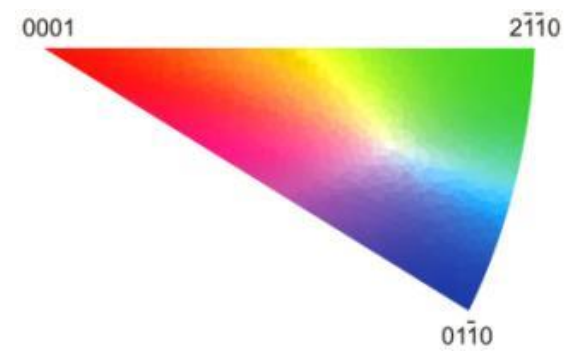

Fig. 33. Key for EBSD pole figure coloring.

Figure 34(a) shows an EBSD map of a ZEK100 sheet rolled at $250^{\circ} \mathrm{C}$ and $10 \%$ reduction. This map contains a larger variety of colors compared to the AZ31B sample, indicating a larger spread in the texture. It was observed that there were more twins and less evidence of dynamic recrystallization. An EBSD map of the ZEK100 sheet rolled at the same conditions $\left(250^{\circ} \mathrm{C}, 10 \%\right.$ reduction) in asymmetric mode is shown in Figure 34 (b). The grains also had a slightly elongated shape with very little recrystallization. It should be noted that due to the relatively large deformation present in the samples following rolling some areas did not produce good EBSD patterns in certain regions and consequently were not correctly indexed by the software. These images would tend to suggest there were very little differences between the microstructure in this asymmetric sample compared to that rolled symmetrically at the same conditions at the 8-Mill (temperature and \% reduction) at this length scale. Comparison with the corresponding results from x-ray texture measurements shown in figures 28 (a) and 28 (b) respectively, shows that the small changes in texture between these two conditions were not sufficient to reflect in significant changes in the EBSD measurements.

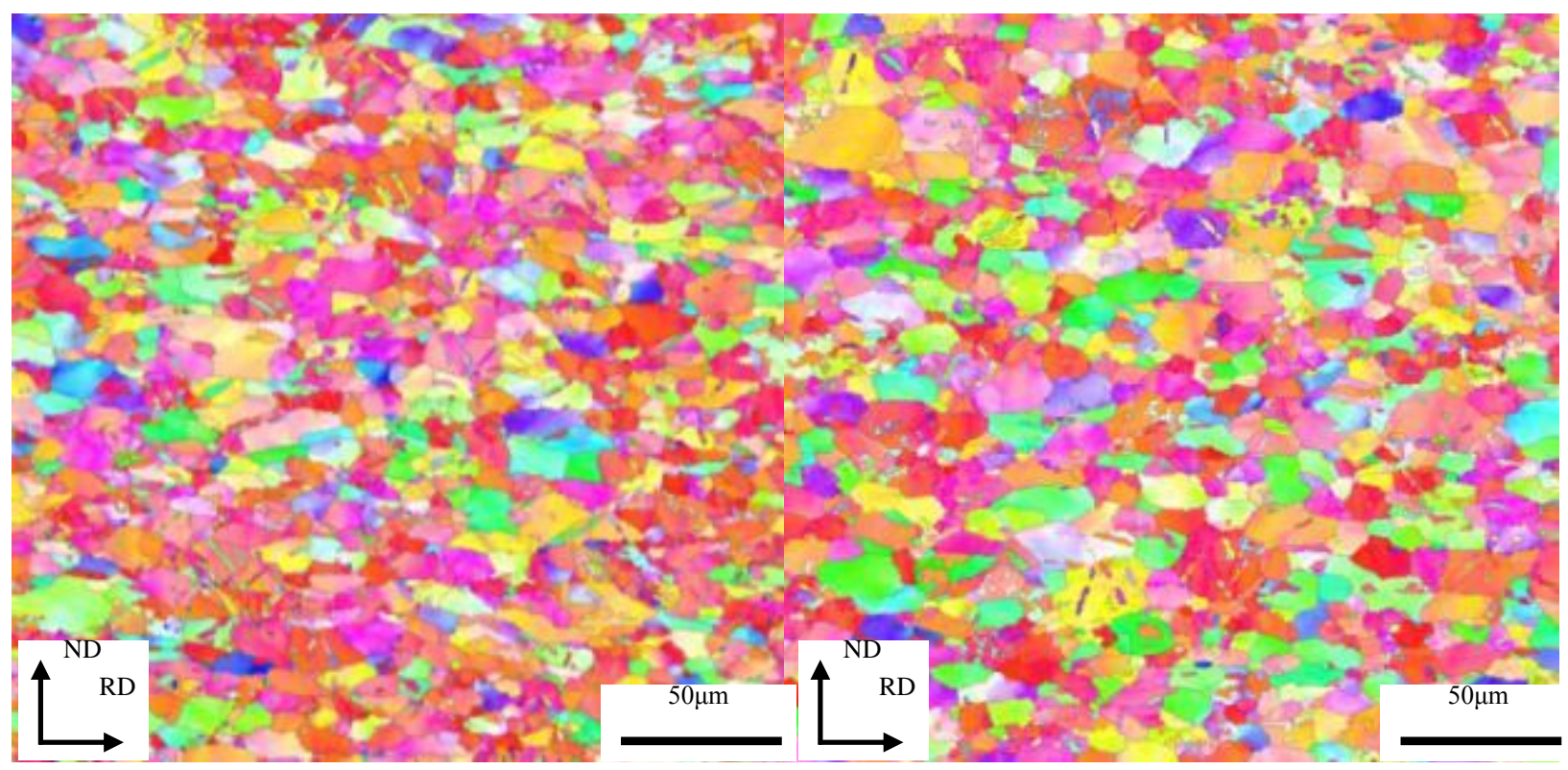

(a)

(b)

Fig. 34. EBSD maps (IPF coloring) of ZEK100 sheet rolled (a) symmetrically and (b) asymmetrically at $250^{\circ} \mathrm{C}$ with $10 \%$ reduction. Maps taken at the centerline of the sheet.

Figure 35 shows ZEK100 samples rolled in symmetric and asymmetric modes at $425^{\circ} \mathrm{C}$ with $10 \%$ reduction. Both samples still showed some elongated, non-recrystallized grains but, compared to the samples deformed at $250^{\circ} \mathrm{C}$, there were more equiaxed, recrystallized grains indicating a significantly 
larger extent of recrystallization when compared to the rolling at $250^{\circ} \mathrm{C}$. There was also less twinning evident in these samples than those deformed at $250^{\circ} \mathrm{C}$. In left side of Figure 35 at least one band of smaller grains can be seen running diagonally across the map. This is thought to be a shear band where the higher level of strain has initiated more dynamic recrystallization and thus decreased the grain size. Comparison between the textures of these samples shown in Figures 30 (a) and (b) suggests that the EBSD results are consistent with $x$-ray textures revealing very little difference between the textures in symmetric and asymmetric rolled samples.

The only sample deformed to 50\% reduction that has been properly studied using EBSD was a sample of ZEK100 rolled asymmetrically at $250^{\circ} \mathrm{C}$, shown in Figure 36 . This study was particularly difficult since the large deformation resulted in an EBSD pattern that was difficult to analyze, as explained earlier. This map was carried out with a higher resolution to allow all features in the microstructure to be analyzed. It can be seen that there were many grains in the material that had not undergone recrystallization; those showing an elongated shape and large angle rotations across the width. There were a larger number of fine recrystallized grains, particularly seen around grain boundaries and in bands across non-recrystallized grains. It is thought that the bands of fine grains across other grains were due to preferential recrystallization on either twins or slip bands. The level of twinning also appears to have been higher in this sample than those rolled with $10 \%$ reduction.

In summary, the EBSD measurements showed results consistent with the bulk x-ray texture measurements. The quality of the EBSD measurements was observed to be poor due to residual deformation thus restricting the use of this technique to processing conditions that imparted little deformation.

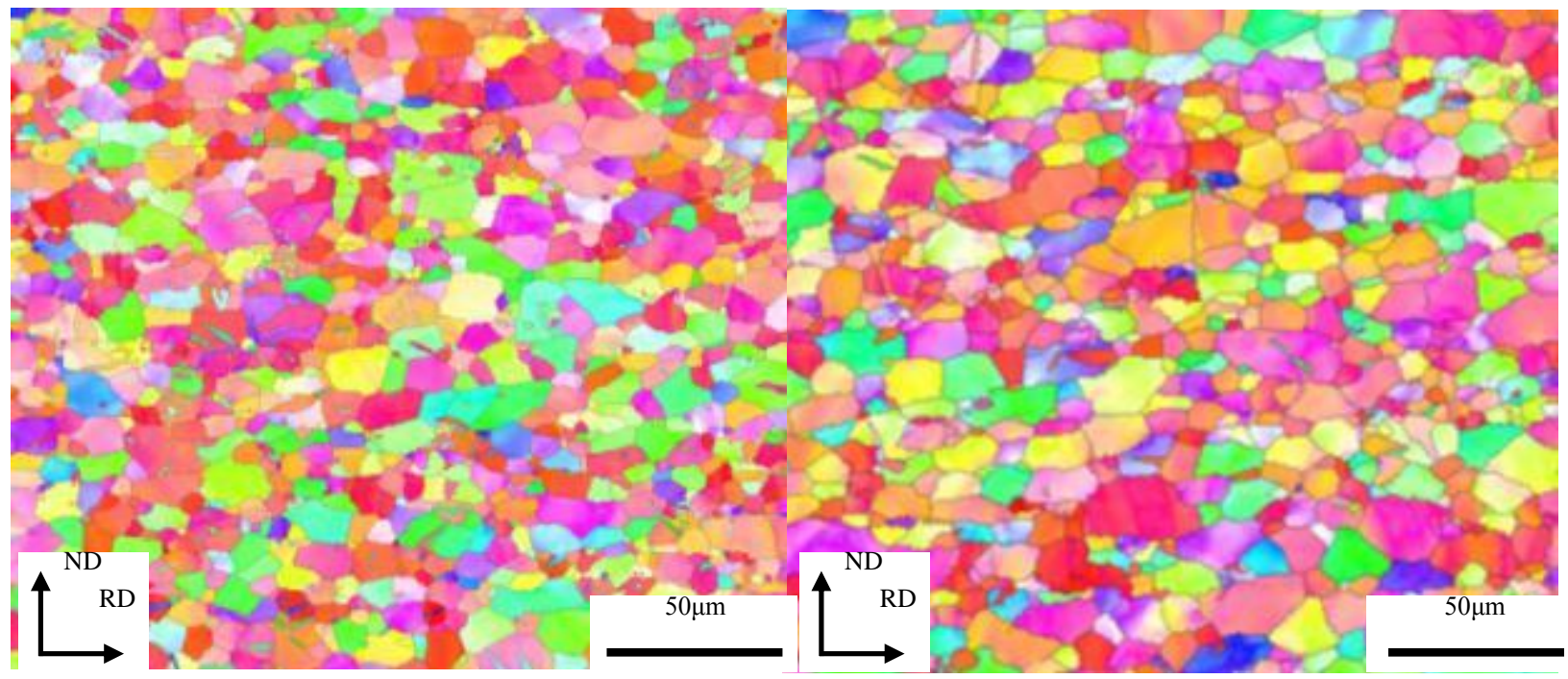

Fig. 35. EBSD maps (IPF coloring) of ZEK100 sheet rolled symmetrically (left) and asymmetrically (right) at $425^{\circ} \mathrm{C}$ with $10 \%$ reduction. Maps taken at the centerline of the sheet. 


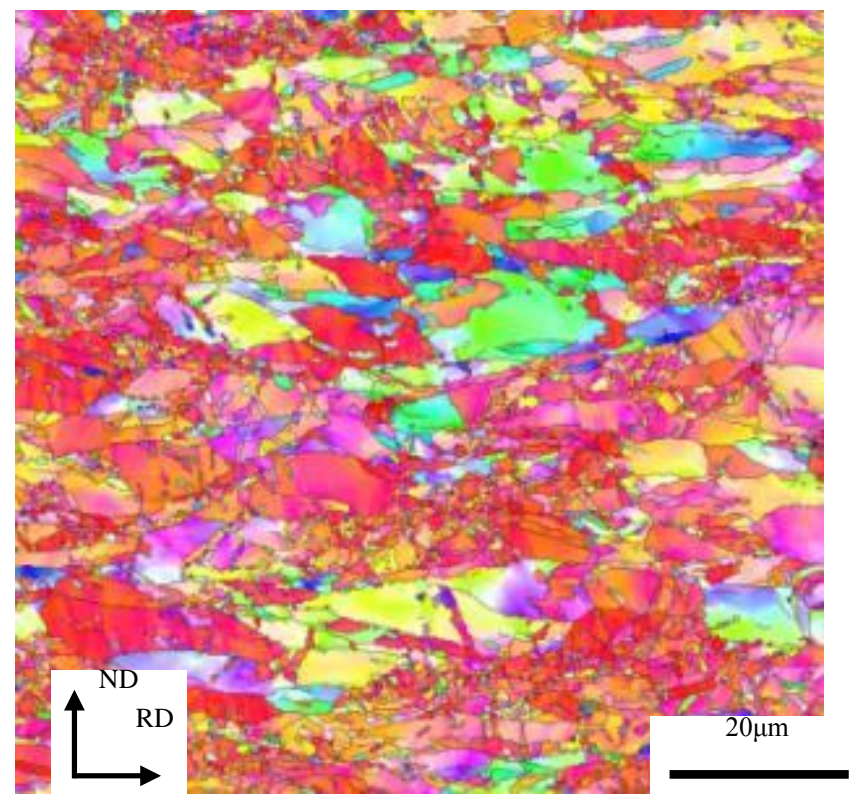

Fig. 36. EBSD map (IPF coloring) of a ZEK100 sheet rolled asymmetrically at $250^{\circ} \mathrm{C}$ with $50 \%$ reduction (map taken at the sheet centerline.) 


\section{FORMABILITY TESTING}

Formabilities of magnesium alloy sheet specimens rolled using MENA's 8-Mill and the FATA Hunter Mill were assessed by dome testing using a $100 \mathrm{~mm}$ spherical ball and the fixture shown in Figure 37 . The sheet to be tested of diameter $138.4 \mathrm{~mm}$, was clamped between the two plates and the whole fixture was heated to a temperature slightly above the desired test temperature (about $3-4^{\circ} \mathrm{C}$ cool-down was observed during the formability tests). The ball which was maintained at the same temperature as the sheet was pushed into the plate from below until failure of the sheet occurred. The thermal inertia provided by the relatively large ball allowed the tests to be conducted in air without additional heating. However, since only one thermocouple placed under the sheet was used to monitor the temperature, it was later found that the temperature of the ball was subject to variations due to thermal history. This design was further modified and an additional thermocouple was used to monitor the temperature of the ball. Load and cross-head displacement were continuously recorded during the test. Surface displacement and strains were recorded using speckle reflectivity. The limiting dome height was used as a guide for formability of the specimens. Boron nitride was used as a high temperature lubricant for the tests. Tests were conducted on as-processed sheets and sheets annealed following rolling; thus depending upon the $\%$ reduction during the rolling process, sheets of different thicknesses were evaluated.

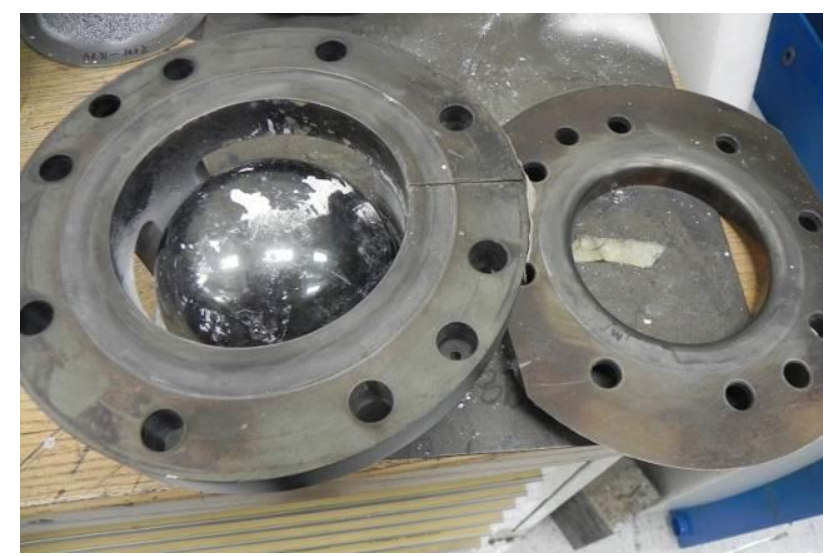

Fig. 37. Fixture used for testing the formability of magnesium sheet.

Figure 38 shows an example of sheets obtained after completion of formability tests performed at $\sim 175^{\circ} \mathrm{C}$. The particular tests were conducted on sheets rolled by a reduction of $50 \%$ at $425^{\circ} \mathrm{C}$. It should be noted that the thickness of the sheets were not the same since these were rolled to different reductions Dome heights were compared to obtain an approximate guidance on the formability of the sheets subject to specified rolling conditions. Variables considered were symmetric vs asymmetric, shear ratio, rolling temperature, and \% reduction in thickness. Tables 4 and 5 show a summary of the limiting dome height data for sheets subject to selected rolling conditions. 


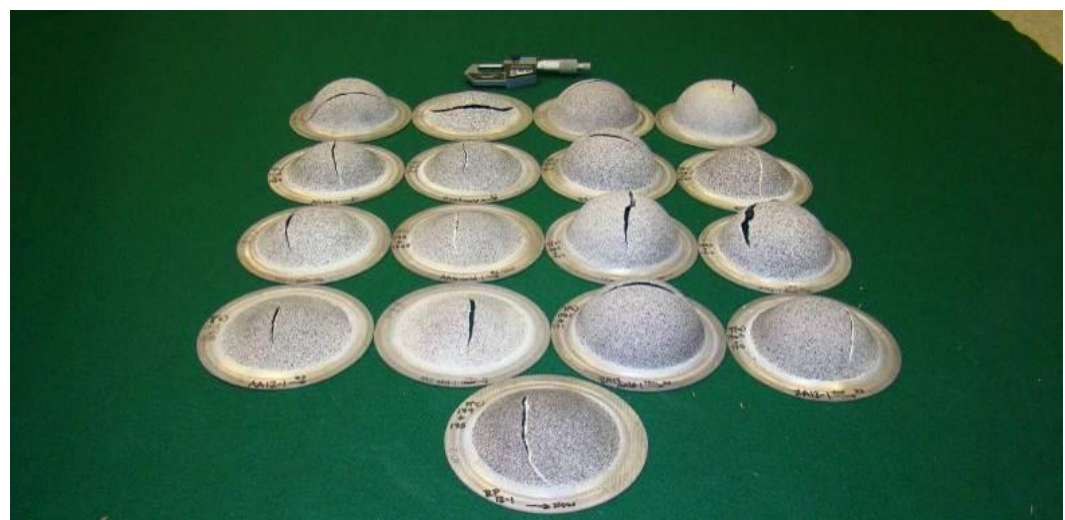

Fig. 38. Typical formed sheets obtained from dome tests on AZ31B and ZEK 100 sheets rolled at $425^{\circ} \mathrm{C}$ to a $50 \%$ reduction in thickness. 
Table 4. Effect of processing conditions on limiting dome heights at $175^{\circ} \mathrm{C}$ for $\mathrm{AZ31B}$

\begin{tabular}{|c|c|c|c|c|c|c|c|}
\hline $\begin{array}{c}\text { Temperature } \\
\left({ }^{\circ} \mathbf{C}\right)\end{array}$ & $\begin{array}{c}\% \\
\text { Reduction }\end{array}$ & $\begin{array}{c}\text { Shear } \\
\text { ratio }\end{array}$ & Mill & Condition & $\begin{array}{c}\text { Final } \\
\text { Thickness }\end{array}$ & $\begin{array}{c}\text { Stroke } \\
\text { Length at } \\
\text { Failure } \\
\text { (in.) }\end{array}$ & $\begin{array}{l}\quad \text { Comments } \\
\text { (Sheet } \\
\text { Processing } \\
\text { conditions) }\end{array}$ \\
\hline 250 & 10 & $1: 1$ & 8-Mill & As rolled & $0.086 "$ & 1.3 & Preheat only \\
\hline 250 & 10 & $1: 1$ & 8-Mill & Annealed & $0.085^{\prime \prime}$ & 0.6 & Preheat only \\
\hline 250 & 10 & $1: 1.35$ & 8-Mill & As-rolled & $0.09 "$ & 0.8 & Preheat only \\
\hline 250 & 10 & $1: 1.35$ & 8-Mill & Annealed & $0.09 "$ & 0.8 & Preheat only \\
\hline 425 & 10 & $1: 1$ & 8-Mill & As rolled & $0.088^{\prime \prime}$ & 0.6 & Preheat only \\
\hline 425 & 10 & $1: 1.35$ & 8-Mill & As rolled & $0.088^{\prime \prime}$ & 0.8 & Preheat only \\
\hline 250 & 50 & $1: 1$ & 8-Mill & As rolled & $0.05 "$ & 1.4 & Preheat only \\
\hline 250 & 50 & $1: 1.35$ & 8-Mill & As rolled & $0.064 "$ & 0.9 & Preheat only \\
\hline 425 & 50 & $1: 1$ & 8-Mill & As rolled & $0.046^{\prime \prime}$ & 0.9 & Preheat only \\
\hline 425 & 50 & $1: 1.35$ & 8-Mill & As rolled & $0.051 "$ & 0.4 & Preheat only \\
\hline 200 & 10 & $1: 1$ & FATA & As rolled & $0.092 ”$ & 0.9 & Isothermal \\
\hline 200 & 10 & $1: 1.35$ & FATA & As rolled & $0.087^{\prime \prime}$ & 1.2 & Isothermal \\
\hline 200 & 10 & $1: 3$ & FATA & As rolled & $0.096 "$ & 0.8 & Isothermal \\
\hline 200 & 25 & $1: 1$ & FATA & As rolled & $0.079 "$ & 1.3 & Isothermal \\
\hline 200 & 25 & $1: 1.35$ & FATA & As rolled & $0.071 "$ & 1.1 & Isothermal \\
\hline
\end{tabular}


Table 5. Effect of processing conditions on limiting dome heights at $175^{\circ} \mathrm{C}$ for $\mathrm{ZEK} 100$

\begin{tabular}{|c|c|c|c|c|c|c|c|}
\hline $\begin{array}{c}\text { Temperature } \\
\left({ }^{\circ} \mathrm{C}\right)\end{array}$ & $\begin{array}{c}\% \\
\text { Reduction }\end{array}$ & $\begin{array}{c}\text { Shear } \\
\text { ratio }\end{array}$ & Mill & Condition & $\begin{array}{c}\text { Final } \\
\text { thickness }\end{array}$ & $\begin{array}{l}\text { Stroke } \\
\text { Length at } \\
\text { Failure } \\
\text { (in.) }\end{array}$ & $\begin{array}{l}\text { Comments } \\
\text { (Sheet processing } \\
\text { conditions) }\end{array}$ \\
\hline 250 & 10 & $1: 1$ & 8-Mill & Rolled & $0.084 "$ & 1.6 & Preheat only \\
\hline 250 & 10 & $1: 1$ & 8-Mill & Annealed & $0.084 "$ & 1.6 & Preheat only \\
\hline 250 & 10 & $1: 1.35$ & 8-Mill & As-rolled & $0.092 "$ & 1.6 & Preheat only \\
\hline 250 & 10 & $1: 1.35$ & 8-Mill & Annealed & $0.092 "$ & 1.6 & Preheat only \\
\hline 425 & 10 & $1: 1$ & 8-Mill & As rolled & $0.089 "$ & 1.4 & Preheat only \\
\hline 425 & 10 & $1: 1.35$ & 8-Mill & As rolled & $0.089 "$ & 1.5 & Preheat only \\
\hline 250 & 50 & $1: 1$ & 8-Mill & As rolled & $0.05 "$ & 1.5 & Preheat only \\
\hline 250 & 50 & $1: 1.35$ & 8-Mill & As rolled & $0.05 "$ & 1.5 & Preheat only \\
\hline 425 & 50 & $1: 1$ & 8-Mill & As rolled & $0.05 "$ & 1.1 & Preheat only \\
\hline 425 & 50 & $1: 1$ & 8-Mill & Annealed & $0.05 "$ & 1.5 & Preheat only \\
\hline 425 & 50 & $1: 1.35$ & 8-Mill & As rolled & $0.05 "$ & 1.1 & Preheat only \\
\hline 425 & 50 & $1: 1.35$ & 8-Mill & Annealed & $0.05^{\prime \prime}$ & 1.5 & Preheat only \\
\hline 200 & 10 & $1: 1$ & FATA & As rolled & $0.088^{\prime \prime}$ & 1.6 & Isothermal \\
\hline 200 & 10 & $1: 1.35$ & FATA & As rolled & $0.083 ”$ & 1.4 & Isothermal \\
\hline 200 & 10 & $1: 3$ & FATA & As rolled & 0.087 & 1.3 & Isothermal \\
\hline 200 & 25 & $1: 1$ & FATA & As rolled & $0.076 "$ & 1.2 & Isothermal \\
\hline 200 & 25 & $1: 1.35$ & FATA & As rolled & $0.069^{\prime}$ & 1.4 & Isothermal \\
\hline
\end{tabular}


Significant conclusions from these tests include:

1. High temperature annealing after asymmetric rolling appeared to reduce the formability of AZ31B (see Figure 39).

2. Formability of AZ31B depended on the temperature, shear ratio, and $\%$ reduction, (Figure 40).

3. There was a $28 \%$ improvement in formability of asymmetrically rolled AZ31B over annealed AZ31B.

4. Formability of ZEK100 appeared to be less sensitive to processing conditions when compared to AZ31B.

5. The average formability of ZEK100 was typically better than that of AZ31B.

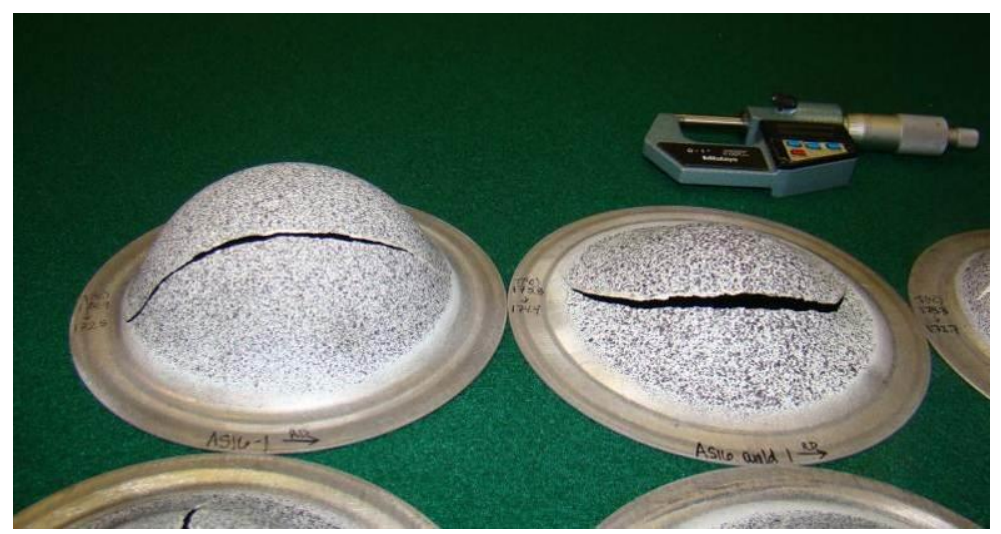

Fig. 39. Annealing of AZ31B results in decreased formability (annealed specimen on the right).
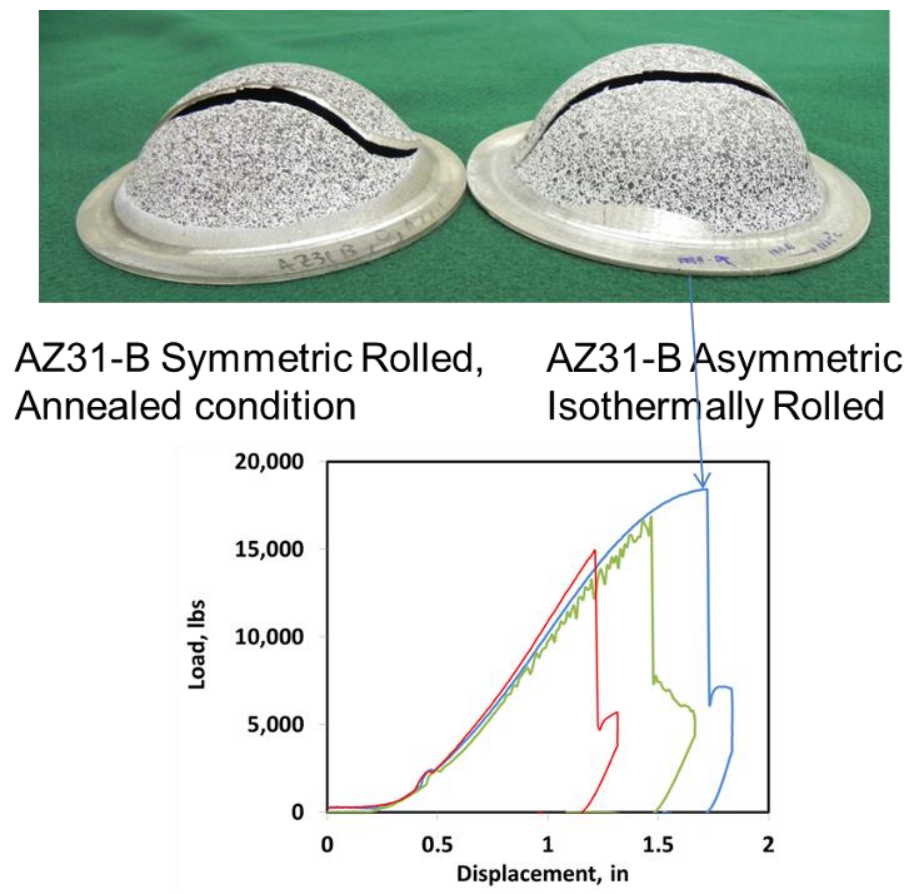

Fig. 40. Results from dome tests on AZ31-B in the annealed condition and in as-rolled condition (asymmetrically rolled). Asymmetric rolling can either improve formability (blue line) or decrease formability (red line) depending on the processing conditions. 


\section{FABRICATE COMPONENTS}

By using the wide magnesium sheet rolled in task 4 on the MENA 8-Mill, demonstration parts for the automotive industry were formed to provide an example of the application of the shear rolling technologies developed in this project. General Motors and Superform USA agreed to form these parts using existing tooling.

The first demonstration part chosen was a section of the firewall for the Panoz Abruzzi sports car. The firewall was chosen as it is a reasonably large part (using a blank approximately $24 \times 28$ inches), with a variety of different strains experienced in different areas. An example of a formed part is shown in Figure 41. The parts were formed in a two-stage process, consisting of a deep draw followed by superplastic forming. Asymmetrically rolled sheets of both AZ31B and ZEK100 were successfully formed into the part as shown in Figure 41.

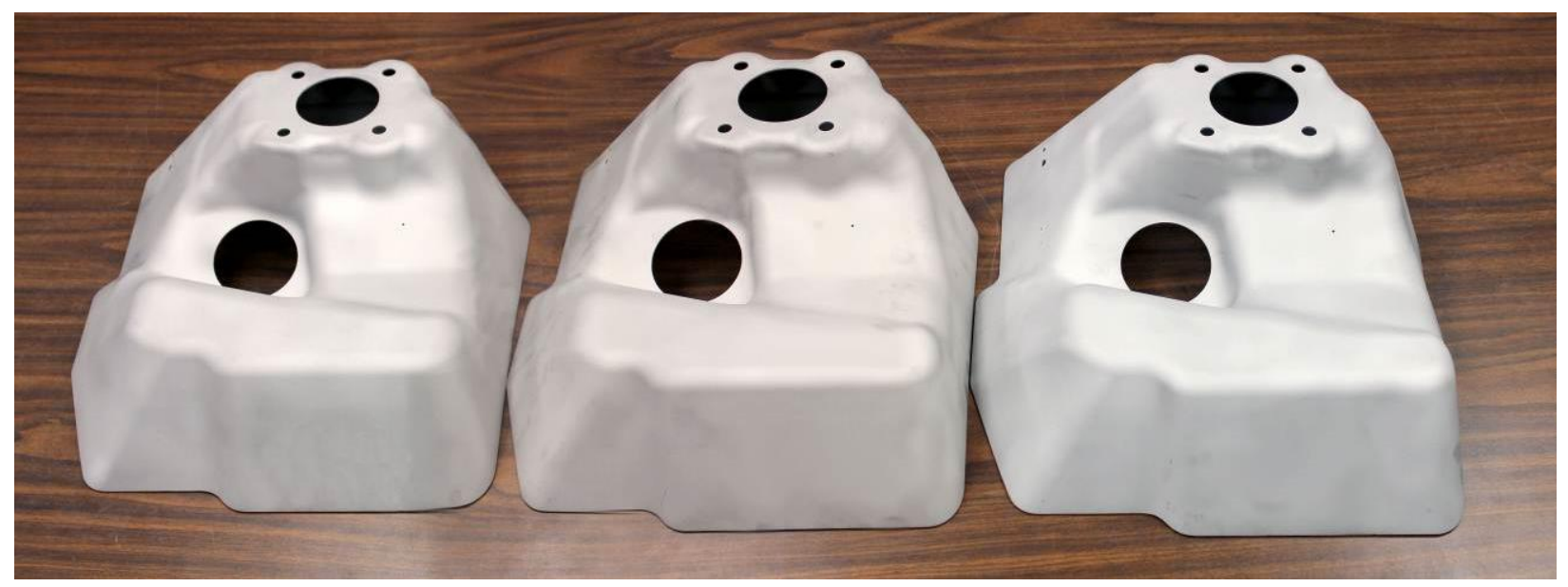

Fig. 41. Photograph showing parts formed at Superform.

The second demonstration of a formed part was the fuel filler cap shown in Figure 42. This work was completely coordinated by MENA in collaboration with their customer and our industrial partner General Motors.

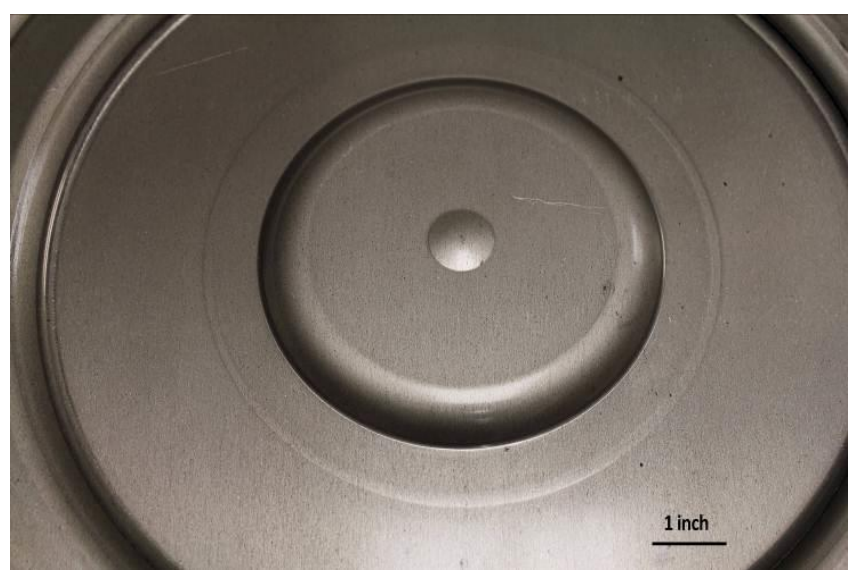

Fig. 42. Photograph showing a part formed at Superform for GM from shear rolled ZEK100. 


\section{BENEFITS ASSESSMENT}

Significant energy savings in automotive applications can be achieved through weight reduction due to the introduction of magnesium based components. For light duty vehicles, a $20 \%$ weight reduction is targeted by $2020^{4}$. The weight reduction potential of magnesium vehicle components (vs. convention steel intensive structures) is about $60-75 \%$. Thus significant benefits can be realized through introduction of magnesium-based components. A number of issues have to be solved including cost, availability, and improving corrosion resistance of magnesium components used in an automotive environment.

This work has clearly shown that once optimized conditions are realized to improve formability, shear rolling has the potential to minimize the cost of magnesium sheet thus accelerating the introduction of magnesium sheet in automotive components. This would facilitate achieving the weight reduction goals targeted for 2020 and thus achieving energy and cost savings. In addition to the automotive applications, there is also interest from aerospace companies on selective use of magnesium components. The introduction of these components can also be facilitated by further success in the development of optimized shear rolling conditions and improved formability.

In addition, this work has made a significant contribution in developing a new product, a unique asymmetric rolling mill that was not previously available on the market. Increased demand for magnesium alloy sheet will create demand for the manufacture and sale of the commercial scale mill resulting in manufacturing jobs within the United States.

\footnotetext{
${ }^{4}$ Carol Shutte and Will Joost, "Lightweighting and Propulsion Materials Roadmapping Workshop Outbrief," Annual Merit Review Presentation, Vehicle Technologies Program, May 16, 2012.
} 


\section{COMMERCIALIZATION}

The following commercialization steps have already been accomplished:

1. A patent application has been filed by ORNL for fixturing and process development.

2. Based upon the developments achieved in this project, a new commercial scale asymmetric rolling mill has been made available for purchase by FATA Hunter. The design for FATA Hunter's pilot scale shear rolling mill received an R\&D 100 award in 2012.

Several additional steps will be pursued to commercialize this technology.

3. New asymmetric rolling processes being developed using the installed mill have shown significant promise in modifying the formability of AZ31B sheet. Patents will be filed as is appropriate and the processing conditions will be transferred to entities that are interested in licensing these patents. These included mill manufacturers like FATA Hunter, material suppliers such as MENA, and end-users in the automotive supply chain.

4. Materials with modified texture will be made available to material suppliers such as MENA and potential end-users such as vehicle OEM manufacturers for them to independently evaluate formability.

5. Peer-reviewed publications will be submitted to aid in the commercialization process. Other means to disseminate information, such as flyers, and exhibits at trade shows will be utilized in the commercialization process. 


\section{ACCOMPLISHMENTS}

- Laboratory-scale asymmetric rolling of shear rolling of magnesium sheet was demonstrated using 3:1 rolls producing 2 -inch wide sheet with modified texture

- One patent application has been filed by ORNL for new fixture and process development

- Tilting of basal poles away from the sheet normal direction was clearly demonstrated by asymmetric rolling

- A unique asymmetric rolling mill equipped with warm rolls for isothermal rolling was designed, manufactured, and installed at ORNL

- A commercial scale mill designed for high throughput manufacture of asymmetrically rolled Mg-alloy sheet based upon this mill by industrial partner (FATA Hunter) won an R \& D 100 award as one of the most significant new products of the year. FATA Hunter has submitted quotations for the new mill design to many commercial entities interested in purchase of new large mills

- Eight-inch wide sheet has been rolled at ORNL using the newly installed mill

- Texture modification using asymmetric rolling was clearly demonstrated for sheet rolled using the new mill

- Improved formability in biaxial testing was initially demonstrated for specific asymmetric rolling processing conditions. These conditions will be evaluated for patentability

- An existing industrial scale mill was modified, and the feasibility of shear rolling wide sheet for commercial use was demonstrated at MENA's facility

- New technology (U. S. patent application submitted) developed at ORNL was implemented in the modification of the mill

- Wide sheet was produced using the newly modified mill

- Keynote presentation was delivered by MENA staff at the TMS Annual Meeting in March 2012.

- Two demonstration automotive components, a firewall and a fuel cap filter, were fabricated using wide sheet manufactured at MENA 


\section{CONCLUSIONS}

1. A new asymmetric rolling mill was successfully designed and fabricated by ORNL and FATA Hunter. This mill won an award as one of the top 100 products developed in 2011 (R \& D 100 award given in 2012).

2. Based upon preliminary rolling trials, commercial magnesium alloys AZ31B (with no rare earth additions) and ZEK100 (with rare earth additions) were selected for further evaluation.

3. Magnesium alloys AZ31B and ZEK100 were successfully rolled in symmetric and asymmetric modes on three different mills with a wide range of processing parameters:

a. Larger reductions caused worse shape control during rolling. Over 25\% reduction did not produce acceptable sheets.

b. ZEK100 could be rolled at lower temperatures than AZ31B.

c. Shear rolling caused the sheet to exit the mill with a substantial curl that can be in either direction. Curling was controlled by a specially designed fixture (Patent Pending).

d. Lubrication was required to roll wider sheet.

4. Sheet microstructure was characterized using optical microscopy and EBSD

a. Shear bands were visible in most rolled samples, more defined in AZ31B than ZEK100.

b. Shear bands in shear rolled material were generally angled into the center of the material away from the rolling direction.

c. There was little difference between the grain structure of samples rolled symmetrically and asymmetrically.

d. A layer of fine grains was often observed at the surface of the sheets, particularly in the shear rolled material.

e. It appears that the slow roll surface underwent more shear strain than the fast roll surface during asymmetric rolling.

f. There was less dynamic recrystallization in ZEK100 than AZ31B.

g. Dynamic recrystallization generally occurred at grain boundaries, twins and deformation bands.

h. Twinning was observed in all samples.

5. The sheet texture was analyzed using XRD and EBSD

a. In AZ31B, lower temperatures and greater reductions of rolling often produced a weaker texture.

b. Asymmetric rolling resulted in substantial tilting of the basal texture towards the rolling direction in AZ31B.

c. Rolling changed the texture in ZEK100 to a more standard split basal texture.

d. Asymmetric rolling with higher reductions significantly altered the texture in ZEK100.

e. The texture was relatively homogeneous through the full thickness of the sheets, with the exception of a thin layer present at the surfaces of some samples.

6. Formability of the sheets was assessed by dome testing at $180^{\circ} \mathrm{C}$. Limiting dome heights were used as guidance for formability. Processing conditions had a significant effect (both positive and negative) on limiting dome heights. 
7. Demonstration parts for automotive applications were successfully formed from shear rolled AZ31B and ZEK100 using sheets processed using conditions developed in this project. 


\section{RECOMMENDATIONS FOR FURTHER WORK}

\subsection{PHASE 2: DESIGN FOR COIL-TO-COIL OPERATION}

The FATA Hunter mill at ORNL was designed such that the pilot mill could be upgradable to allow coil-to-coil operation. This option includes the addition of hot coilers, with their associated pinch rolls, deflector rolls, and threading aprons, as well as an entry/exit reel assembly with coil car, a cooling unit and an upgrade to the mill control system for coiler tension control, plus miscellaneous items such as work roll brushes and hydraulic system upgrades. As with the roller tables, the hot coiler boxes are heated with recirculated hot air to eliminate the dangers of radiant heating.

In this coil to coil configuration, a slab of preheated magnesium would be placed on one of the roller tables and rolled in a reversing manner until it reaches a thickness of $0.25 \mathrm{in}$. $(6 \mathrm{~mm})$. At this point it is guided into one of the hot coilers and is then rolled in the coil-to-coil mode until the desired thickness is reached. By selecting the correct starting roller table and pass schedule the final gauge is reached when the mill is running from the left- hand coiler. On this final pass the strip is guided past the righthand hot coiler to the cooler and then the entry/exit reel assembly. The cooler quenches the material to prevent grain growth in the slowly cooling coil. Cooling is through a water spray followed by an air knife to remove water from the strip surface; any remaining water being immediately evaporated by the residual heat in the strip prior to coiling. Air cooling, however, is available as an option. The finished coil is then removed from the mandrel by means of the coil car. The coil car has an integral hold-down snubber roll to provide stability to the narrow coil. The coil is then removed from the coil car using a forklift truck or overhead crane.

Although the mill can work with slab as described above, it is more likely to be used with twin roll cast material. In that case a $0.25 \mathrm{in}$. $(6 \mathrm{~mm})$ thick coil of room temperature magnesium is placed onto the coil car by means of a forklift truck or overhead crane. The coil is then loaded onto the mandrel of the entry/exit reel assembly and the coil is unwound through the mill (which operates in a pinch roll mode) into the left-hand hot coiler. The metal is then preheated to the rolling temperature in the coil box before starting the coil-to-coil rolling process outlined in method (1) above. Alternatively, to improve

mill efficiency, the initial 0.25 in. $(6 \mathrm{~mm})$ coil could be pre-heated off line and then loaded onto the coil car. While considerable progress was made during this project, more detailed studies are required to optimize shear rolling process for industrial practice. In order to more fully develop commercial shear rolling of magnesium more detailed study is needed.

\subsection{ASYMMETRIC ROLLING PROCESS DEVELOPMENT AND EVALUATION}

The following are suggested future work for process development and process evaluation.

1. A thorough parametric study is needed to understand the effect of $\%$ reduction, temperature, and shear ratio on the development of texture.

2. Effect of complex combination of processing paths (in contrast to simple paths outlined above) on texture development should be evaluated.

3. Effect of rare earth elements additions to alloys in \# 1 and \# 2 should be evaluated.

4. Effect of initial microstructure (in particular the grain size and initial texture) on \#1, \#2, and \#3 outlined above should be evaluated.

5. The effects of processing and composition variables on formability should be better understood. 